\title{
Smartphone Apps for the Treatment of Mental Disorders: Systematic Review
}

Ignacio Miralles $^{1^{*}}, \mathrm{PhD}$; Carlos Granel1 ${ }^{1^{*}}, \mathrm{PhD}$; Laura Díaz-Sanahuja ${ }^{1^{*}}$, PsyM; William Van Woensel ${ }^{2^{*}}, \mathrm{PhD}$; Juana Bretón-López ${ }^{1,3 *}, \mathrm{PhD}$; Adriana Mira ${ }^{4 *}, \mathrm{PhD}$; Diana Castilla ${ }^{3,4^{*}}, \mathrm{PhD} ;$ Sven Casteleyn ${ }^{1 *}, \mathrm{PhD}$

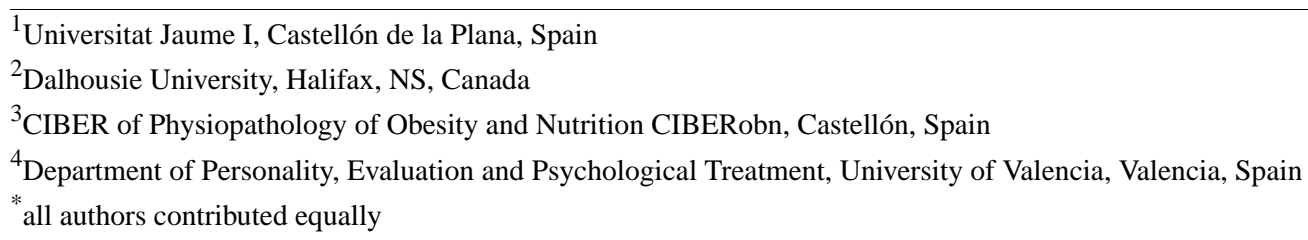

Corresponding Author:

Ignacio Miralles, $\mathrm{PhD}$

Universitat Jaume I

Av Vicent Sos Baynat, s/n

Castellón de la Plana, 12071

Spain

Phone: 34964728000

Fax: 34964729016

Email: mirallei@uji.es

\section{Abstract}

Background: Smartphone apps are an increasingly popular means for delivering psychological interventions to patients suffering from a mental disorder. In line with this popularity, there is a need to analyze and summarize the state of the art, both from a psychological and technical perspective.

Objective: This study aimed to systematically review the literature on the use of smartphones for psychological interventions. Our systematic review has the following objectives: (1) analyze the coverage of mental disorders in research articles per year; (2) study the types of assessment in research articles per mental disorder per year; (3) map the use of advanced technical features, such as sensors, and novel software features, such as personalization and social media, per mental disorder; (4) provide an overview of smartphone apps per mental disorder; and (5) provide an overview of the key characteristics of empirical assessments with rigorous designs (ie, randomized controlled trials [RCTs]).

Methods: The Preferred Reporting Items for Systematic Reviews and Meta-Analyses guidelines for systematic reviews were followed. We performed searches in Scopus, Web of Science, American Psychological Association PsycNET, and Medical Literature Analysis and Retrieval System Online, covering a period of 6 years (2013-2018). We included papers that described the use of smartphone apps to deliver psychological interventions for known mental disorders. We formed multidisciplinary teams, comprising experts in psychology and computer science, to select and classify articles based on psychological and technical features.

Results: We found 158 articles that met the inclusion criteria. We observed an increasing interest in smartphone-based interventions over time. Most research targeted disorders with high prevalence, that is, depressive $(31 / 158,19.6 \%)$ and anxiety disorders $(18 / 158,11.4 \%)$. Of the total, $72.7 \%$ (115/158) of the papers focused on six mental disorders: depression, anxiety, trauma and stressor-related, substance-related and addiction, schizophrenia spectrum, and other psychotic disorders, or a combination of disorders. More than half of known mental disorders were not or very scarcely $(<3 \%)$ represented. An increasing number of studies were dedicated to assessing clinical effects, but RCTs were still a minority $(25 / 158,15.8 \%)$. From a technical viewpoint, interventions were leveraging the improved modalities (screen and sound) and interactivity of smartphones but only sparingly leveraged their truly novel capabilities, such as sensors, alternative delivery paradigms, and analytical methods.

Conclusions: There is a need for designing interventions for the full breadth of mental disorders, rather than primarily focusing on most prevalent disorders. We further contend that an increasingly systematic focus, that is, involving RCTs, is needed to improve the robustness and trustworthiness of assessments. Regarding technical aspects, we argue that further exploration and 
innovative use of the novel capabilities of smartphones are needed to fully realize their potential for the treatment of mental health disorders.

(JMIR Mhealth Uhealth 2020;8(4):e14897) doi: 10.2196/14897

\section{KEYWORDS}

mental health; mental disorders; treatment; intervention; mHealth; smartphone; mobile phone; mobile apps; systematic review

\section{Introduction}

\section{Background}

The popularity of smartphones has skyrocketed over the last decade. Different sources estimate that around $35 \%$ of people worldwide own a smartphone; even much higher penetration rates are reported in developed countries (ranging from $76 \%$ in the United Kingdom to 95\% in South Korea) [1,2]. Smartphones are fast becoming the most common mobile phone, even in emerging economies [2]. Smartphones distinguish themselves from other types of mobile phones in several ways: (1) improved modality (screen and sound), interaction, and computational resources, which support sophisticated software applications called (mobile) apps; (2) built-in mobile sensors, which allow apps to access various measurements, such as the user's current position, motion, ambient light, and sound; and (3) connectivity hardware (Wi-Fi and Bluetooth), which allows virtually ubiquitous internet connections, as well as connections to nearby wireless hardware (eg, headsets and physiological sensors). A variety of mobile apps have been developed, conveniently installable from so-called app stores, which address a wide range of personal, entertainment, and business needs. In 2017, 2.8 and 2.2 million apps were available from the Google Play and Apple App stores, respectively; collectively, these were downloaded a total of 178.1 billion times [3].

Researchers quickly realized the potential of mobile apps in health [4] and mental health [5], with systematic reviews on related research, that is, targeting mobile health (mHealth) apps, appearing as early as 2011 [5]. Whereas traditional telehealth [6] and cellphone-based [7] systems are limited to SMS, telephone, or video calls, smartphones present a more versatile, powerful, and personalized platform for a holistic set of care tasks, including patient screening, symptom and disorder assessment, psychoeducation, intervention delivery, progress monitoring, and relapse prevention [5]. By providing these health tasks via smartphone apps, albeit partially or combined with a therapist's intervention, a number of obstacles for mental health care are reduced such as therapist workload, lack of qualified personnel, geographic barriers, and attitudinal barriers to seek treatment. New opportunities arise as well, such as improving assessment by leveraging built-in smartphone sensors (eg, biofeedback and motion) and analyzing device usage, and providing ecological interventions directly to the patient when they are most needed, as determined by in situ assessments [8-14].

This is a timely evolution, as reported mental health problems are becoming increasingly prevalent. Trautmann et al [15] estimated that over $50 \%$ of the population of high- and middle-income countries suffers from at least one mental disorder in their life, with a significant impact on their quality of life and an overall annual economic cost of US \$2.5 trillion (2010) and rising. According to the latest US annual survey [16], there is an estimated 12-month mental disorder prevalence of $18.3 \%$ among adults ( $4.2 \%$ for serious mental illness). Mobile mental health interventions have reported promising mental health outcomes [17-19], large acceptance rates by patients [20], and increased sustainability and preservation of treatment effects [21]. Hence, owing to their ability to reduce obstacles for mental health care, these interventions can be leveraged to meet present-day mental health challenges. Nevertheless, we find that the possibilities of current smartphone technology have only just been tapped, and further research is needed to explore them fully [22], as are studies to rigorously analyze the empirical effectiveness of these systems [22,23]. For driving and steering such future research, there is a continuous need to establish a state of the art, which comprehensively reviews current focal points on psychological (ie, type of disorder and evaluation) and technological factors (smartphone capabilities, technologies, and features used). Such a review should include both exploratory research, which investigates technological opportunities, and empirical research, which establishes robust empirical evidence for the efficacy of smartphone interventions. Previous mobile mental health reviews have become dated [24-26], while more recent studies only consider specific mental disorders; for example, cognitive impairment [27], alcohol and substance abuse [28], anxiety [17]; only consider technologies, for example, text messaging [29] and SMS messages [11]; or focus solely on efficacy, usability, and feasibility of interventions realized by mHealth (mobile health, referring to the use of mobile computing and communication technologies in health care [29]) interventions [11,17,27,30,31].

\section{Objectives}

We provide a systematic review that studies the recent (2013-2018) research on smartphone app-based interventions for mental disorders. Specifically, we aimed to analyze and summarize relevant research to (1) analyze the coverage of mental disorders in research articles per year; (2) study the types of assessment in research articles per mental disorder per year; (3) map the use of sensors, software features, and analytical capabilities of smartphones per mental disorder; (4) provide an overview of mobile smartphone apps per mental disorder; and (5) provide an overview of the key characteristics from empirical assessments with rigorous designs (ie, randomized controlled trials [RCTs]). As a counterbalance to our focus on smartphone interventions, we also briefly discuss potential risks such as lack of proven effectiveness, possibility for harm, and breach of privacy. 


\section{Methods}

\section{Search and Study Selection}

This systematic review uses the Preferred Reporting Items for Systematic Reviews and Meta-Analyses (PRISMA) [32] as a guideline. We performed an extensive search of scientific databases, that is, Scopus, Web of Science (WoS), American Psychological Association (APA) PsycNET, and Medical Literature Analysis and Retrieval System Online (MEDLINE), using queries that combined search terms related to the psychological (eg, psychology, psychological, mental disorder and intervention) and the technological dimensions (eg, mobile device, smartphone and mHealth) using logical operators. All database-specific queries were semantically equivalent but formulated using the different syntaxes and technical support of the respective search engines. The queries were launched on March 9, 2018, covering results from 2013 until March 2018, and relaunched on July 13, 2019, to cover the full year of 2018. Keywords and queries can be found in Multimedia Appendices 1 and 2 .

All resulting publications were downloaded, and duplicates were removed. All papers were equally divided among four multidisciplinary groups of two members, each comprising one computer scientist and one psychologist. Publications were initially screened based on the inclusion/exclusion criteria (IC/EC), using title, abstract, and keywords. Subsequently, papers that were still inconclusive, that is, after initially screening for their title, abstract, and keywords, were fully reviewed to check their eligibility using the IC/EC. Both during initial screening and full-text screening for eligibility, both team members processed the group's assigned papers independently and discussed their observations before making a final decision. In case of disagreement, a third reviewer was assigned, and a final decision was made collaboratively.

\section{Inclusion Criteria}

Articles fulfilling all the following IC were included in our systematic review: (IC1) Full research articles published in an international journal or conference proceedings between January 1, 2013, and December 31, 2018, written in English, and where a full text was available; (IC2) Primary research articles, that is, articles that produce first-hand contributions to the research field; (IC3) Articles explicitly describing the use of a smartphone app for the delivery of psychological intervention(s) for mental disorder(s), whereby (a) smartphones are used as delivery platform and at least one smartphone-specific feature is used, thus going beyond regular mobile phone features (eg, SMS messages and phone calls) and standard content delivery (eg, nonmobile and generic websites); (b) the targeted mental disorders are found in the Diagnostic and Statistical manual of Mental Disorders (DSM-5) [33]; and (IC4) Articles including either exploratory research (ie, investigating technological opportunities) or empirical research (ie, establishing robust empirical evidence). For exploratory research, an explicit description on the use of the smartphone app for a psychological intervention is required. For empirical research, there were no restrictions on study design. Study protocols were also included.

\section{Exclusions Criteria}

EC were all sources that do not comply with the IC: (EC1) All research articles published before 2013 or after 2018, not written in English, not published as a full paper in an international journal or conference. This excludes articles published in any other outlet, such as workshops, discussion forums, colloquia, patent descriptions, white papers, and other types of publications, for example, posters, demo papers, tutorial paper, editorials, or extended abstracts; (EC2) All secondary research articles, that is, articles that use primary research articles to derive results such as reviews, systematic maps, meta-analysis, synthesis, and comments; (EC3) Any article not explicitly describing the use of smartphones as the primary mode of delivering psychological interventions for mental disorders. This excludes articles addressing nonmental disorders (eg, cancer) or symptoms (eg, stress), as well as articles describing the use of other mobile devices (eg, wearables, smart watches, and tablets) or using smartphones only as a regular phone (eg, SMS messages and phone calls); and (EC4) Any article that only superficially describes the application of a smartphone app to a mental disorder-that is, without providing empirical evaluation data, or lacking a detailed description on the use of the smartphone app for delivering psychological interventions for mental disorders. This includes philosophical papers, vision papers, or papers solely focusing on a technical innovation without an accompanying mobile app and/or targeted mental disorder.

\section{Classification of Studies}

All included studies were classified according to technologyand psychology-related dimensions. Additionally, we recorded the name of the app as well.

The technology-related dimensions included the following: (1) built-in sensors: accelerometer, gyroscope, GPS, microphone, and camera; (2) software features: prompting (any kind of proactive prompting to the patient, for example, reminders, notifications, or motivational messages), health care provider communication (directly communicating with a health care provider through the mobile app), progress (allowing patients to monitor their progress throughout the intervention), assessment (capability to [psychologically] assess the patient, including self-assessment [eg, questionnaire] and automatic assessment [eg, based on smartphone usage patterns]), social (availability of social networking and peer communication, such as forums, chat, messaging, and sharing of experiences or information sources), personalization (ability to customize/personalize some aspects of the mobile app toward the patient), learning (any kind of learning material or support presented to the patient), in situ use (explicit support for using the mobile app in the patient's natural environment [ecological], that is, which allows real-time [momentary] interventions when they are most needed), gamification (use of game elements and principles), context awareness (capability of detecting the context/environment of the patient, for example, location, ambient sound, and text/call history), virtual reality (VR, use of virtual environments as delivery paradigm), and augmented reality (use of augmented environments as delivery paradigm); and (3) analytics: use of advanced software algorithms in the 
mobile app or supporting infrastructure (ie, server side)_including machine learning, behavioral analysis, activity analysis, and spatial analysis.

The psychology-related dimensions included the following: (1) mental disorders: the considered mental disorders are based on DSM-5 [33]. In addition to the well-established diagnosis categories from DSM-5, we also considered a suicidal behavior disorder/non suicidal self-injury category, as this condition is very well represented in the literature and recognized as a condition for further study in DSM-5 (ie, likely to be included in future versions). In cases where the smartphone app focuses on multiple disorders, we distinguished between (a) comorbid disorders, that is, those specifically focusing on comorbidity, and (b) various disorders, that is, those delivering treatment(s) for different disorders (not co-occurring, that is, in different patients); and (2) approaches to psychotherapy: the different approaches to psychotherapy are based on the existing theories, which guide psychologists through the process of understanding patients and their mental disorders and developing solutions. Taking into account different treatment modalities and psychological frameworks, approaches to psychotherapy fall into eight broad categories: cognitive behavioral therapies, humanistic therapies, systemic therapies, psychoanalysis therapies, third wave therapies, transdiagnostic therapies, positive psychotherapy, and others.

Finally, the study-related dimensions included the assessment type: Effect, Usability/user experience (short: Usability/UX), Effect and Usability/UX and No Assessment. Effect indicates that the authors reported results about the smartphone app's effects on the participants' clinical symptomatology. Usability and user experience, as defined by ISO 9241-210:2010, that is, the International Standard on Ergonomics of human System Interaction [34], indicates that the authors assessed variables such as usability, user acceptance, opinion and satisfaction, feasibility, and intention to use. Effect and Usability/UX denotes that the authors assessed Effect as well as Usability and UX. Finally, No Assessment refers to those cases where no assessment was reported, for example, including study protocols or technical descriptions of the smartphone apps delivering psychological interventions for mental disorders.

\section{Data and Software Availability}

For transparency and reproducibility, we published the resulting data, code, and instructions on GitHub (San Francisco, California) and archived the work in Zenodo [35]. The GitHub repository includes a literate programming document that combines text, data preprocessing, analysis, and visualizations.

\section{Results}

\section{Study Inclusion}

Figure 1 shows the results of the systematic review processes according to the PRISMA data flow chart. During the identification phase, we identified 13,219 studies from the four different Web-based sources (Scopus, WoS, APA PsycNET, and MEDLINE), which we reduced to 6116 after removing duplicates. After the screening phase, that is, based on title, abstract, and keywords, we retained 392 articles. The eligibility assessment, that is, based on the full paper, led to a final set of 158 papers. More details can be found in Figure 1. 
Figure 1. Preferred Reporting Items for Systematic Reviews and Meta-Analyses flow diagram for the systematic review. WoS: Web of Science.

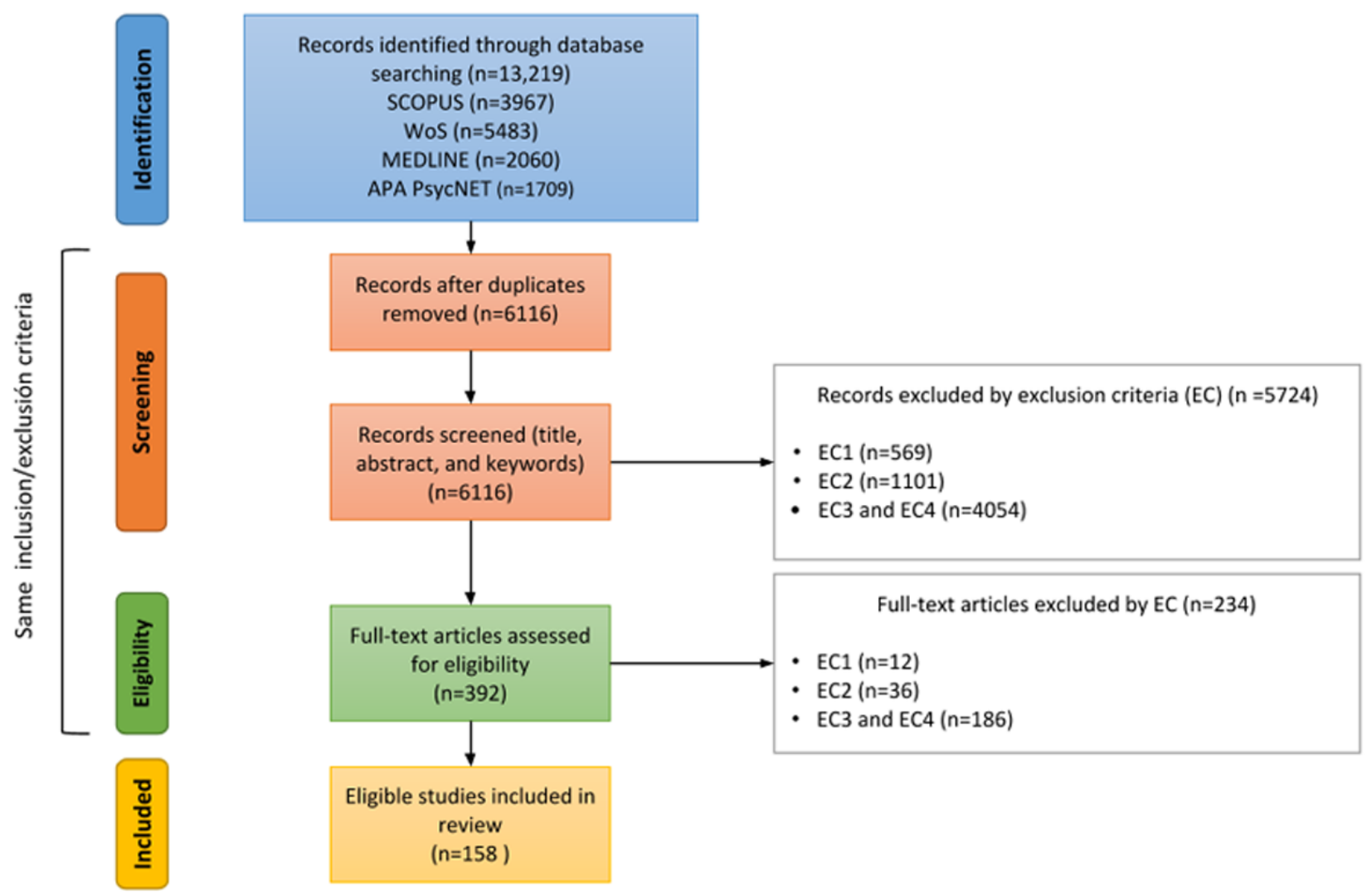

\section{Evolution of Research and Types of Assessment}

Figure 2 shows the temporal distribution of research over the study period 2013-2018, along with their reported assessment type. Overall, we observed a positive evolution of the amount of research over time, steadily increasing from only few (7) articles in 2013 to a much larger amount (60) in 2018.

In Table 1, we show the distribution of assessment types for the reviewed studies. The majority of articles $(113 / 158,71.5 \%)$ reported some kind of assessment. Looking at the distribution of assessment types over time (Figure 2; percentages), we observe an overall slow proportional increase of studies with an assessment (2015 appears to have been an outlier). Regarding the type of assessment, we observe that only a fifth of the articles with assessment $(22 / 113,19.5 \%)$ focus specifically on the effect of intervention on clinical symptomatology $(15 / 113,13.9 \%$ of all studies). Although we see an absolute increase over the last 2 years (in line with the overall increase of studies in general), the sharp increase in 2017 could not be confirmed in 2018 in proportional terms. The proportional amount of usability/UX assessments steadily rose over the years, with an outlier in 2016, where it counteracted a sharp drop in mixed assessments. Caution should be taken with interpreting and generalizing these results; additional data over a larger timeframe are needed.

Orthogonal to the general type of assessment, we also considered other characteristics of the assessment-that is, whether it features an RCT over a long timeframe, or a pilot RCT; or supplies less empirically rigorous results, such as qualitative studies, feasibility studies, case studies (eg, $\mathrm{n}$ of one clinical trials) or usability studies. From Table 1, we observe that only a small minority of studies performed an RCT assessment $(25 / 113,22.1 \%$ of all studies with assessment; $25 / 158,15.8 \%$ overall) and only a handful of papers $(7 / 113,6.2 \% ; 7 / 158,4.4 \%$ overall) performed a pilot RCT. Moreover, only a minority of all RCTs $(9 / 25,36 \% ; 9 / 158,5.7 \%$ overall) and pilot RCTs (2/7, $29 \% ; 2 / 158,1.3 \%$ overall) were focused specifically on effect assessments. 
Figure 2. Temporal trend and number of articles published per assessment type.

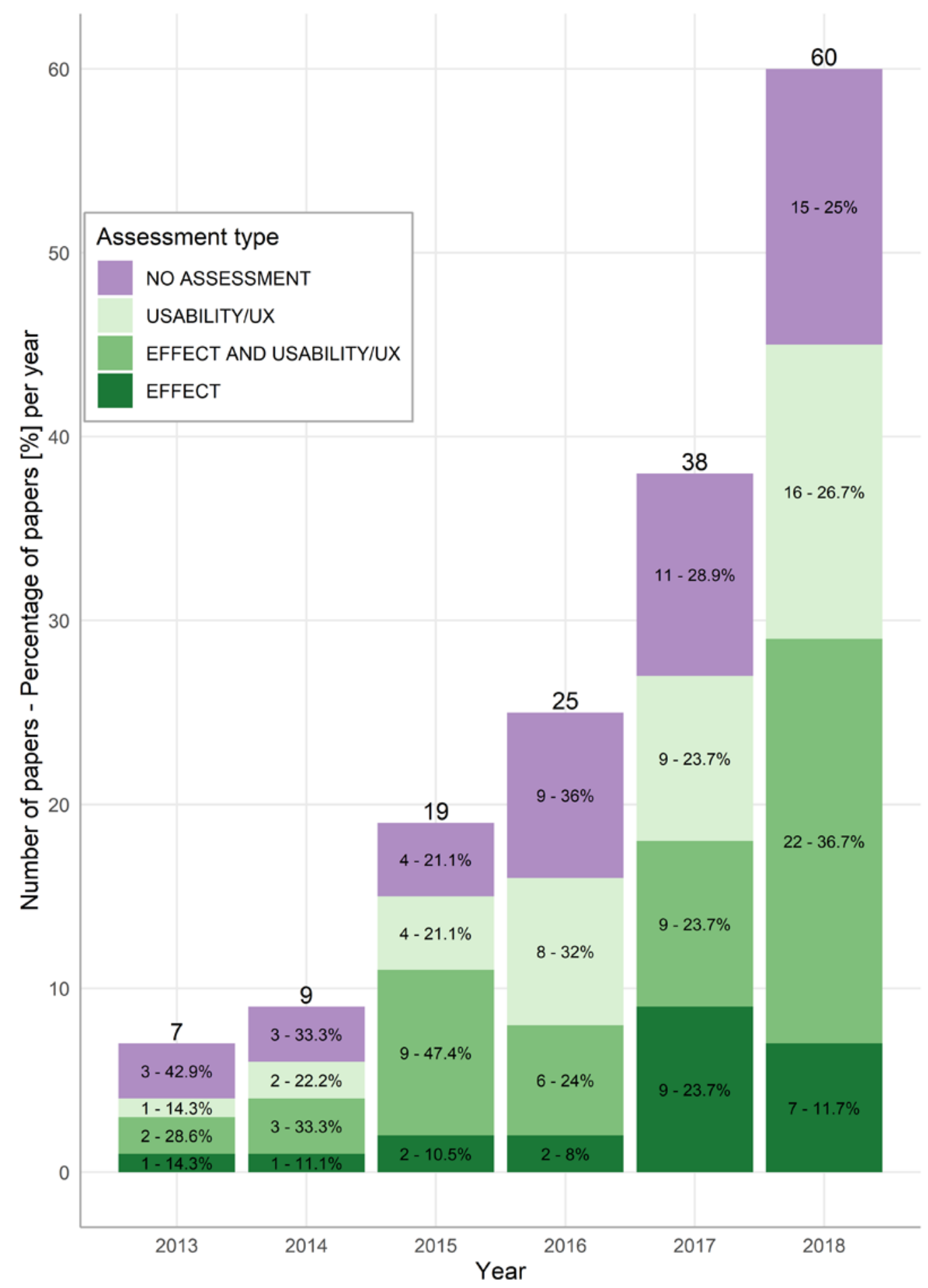


Table 1. Distribution of assessment type.

\begin{tabular}{llll}
\hline Assessment types & All, n (\%) & RCT, $\mathrm{n}(\%)$ & Pilot RCT, n (\%) \\
\hline No assessment (total) & $45(28.5)^{\mathrm{b}}$ & $\mathrm{N}^{\mathrm{a}} \mathrm{A}^{\mathrm{c}}$ & N/A \\
Assessment (total) & $113(71.5)^{\mathrm{b}}$ & $25(22.1)^{\mathrm{d}}$ & $7(6.2)^{\mathrm{d}}$ \\
$\quad$ Usability/UX & $40(35.4)^{\mathrm{d}}$ & $2(8)^{\mathrm{f}}$ & $0(0)^{\mathrm{f}}$ \\
$\quad$ Effect + usability/UX & $51(45.1)^{\mathrm{d}}$ & $14(56)^{\mathrm{f}}$ & $5(71)^{\mathrm{f}}$ \\
$\quad$ Effect & $22(19.5)^{\mathrm{d}}$ & $9(36)^{\mathrm{f}}$ & $2(29)^{\mathrm{f}}$ \\
\hline
\end{tabular}

${ }^{\mathrm{a}} \mathrm{RCT}$ : randomized controlled trial.

${ }^{b}$ Percentage based on the total number of studies $(\mathrm{N}=158)$.

${ }^{\mathrm{c}} \mathrm{N} / \mathrm{A}$ : not applicable.

${ }^{\mathrm{d}}$ Percentage based on the number of studies with an assessment $(\mathrm{N}=113)$.

${ }^{\mathrm{e}} \mathrm{UX}$ : user experience.

${ }^{\mathrm{f}}$ Percentage based on the number of RCT studies $(\mathrm{N}=25)$ and Pilot RCT studies $(\mathrm{N}=7)$, respectively.

\section{Covered Mental Disorders}

Figure 3 shows the number of studies per mental disorder, ranked in ascending order and subcategorized according to the type of assessment. Depressive disorders $(31 / 158,19.6 \%)$ is the most commonly addressed mental disorder. Note that the category of various disorders includes apps addressing multiples disorders, where serious mental illness, depressive and anxiety disorders are most represented. Collectively, the top six mental disorders account for $73.4 \%$ (116/158) of all studies included in the search. Regarding comorbid disorders, we point out that the majority of papers were related to a specific dual pathology, that is, where a psychological disorder coexisted with the abuse of substances. One case in this category was focused on neurodevelopmental disorders and elimination disorders. For all remaining mental disorders from DSM-5 [33] (not shown in Figure 3), we did not find studies that met our IC. 
Figure 3. Distribution of articles per mental disorder, categorized according to assessment type. Aggregated results of assessment types: No assessment 45/158 (28.5\%), Usability/UX 40/158 (25.3\%), Effect + usability/UX 51/158 (32.3\%), Effect 22/158 (13.9\%).

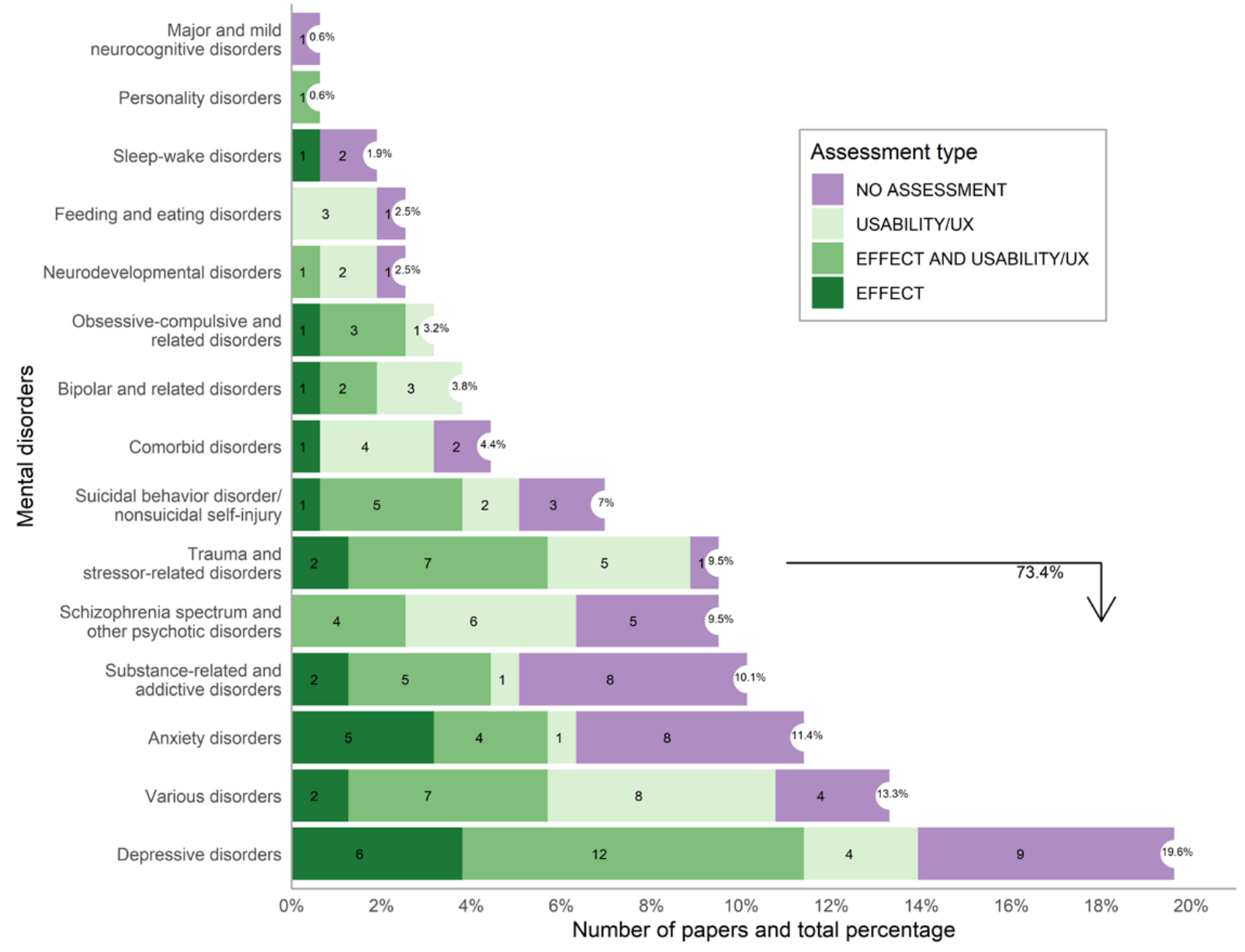

Figure 4 shows the temporal trend of the top six mental disorders targeted by studies over the period 2013-2018. Overall, we observed an increasing number of published articles related to the top six mental disorders over time, with a significant increase since 2015. We also noted that the relative ranking of the top six mental disorders is largely maintained since 2015 , with two notable exceptions: trauma and stressor-related disorders sharply decreased in 2018, and various disorders (ie, the app can be utilized to target multiple independent [noncomorbid] disorders) significantly increased in the last 2 years, reaching the first and second positions, respectively. Finally, we point out the doubling of research on depressive disorders-which was already well researched previously-in 2018, and the fact that research on substance-related and addictive disorders only started in 2015, yet it has been steadily growing since to reach the third position in 2018 . 
Figure 4. Temporal distribution of articles published for the top 6 mental disorders.

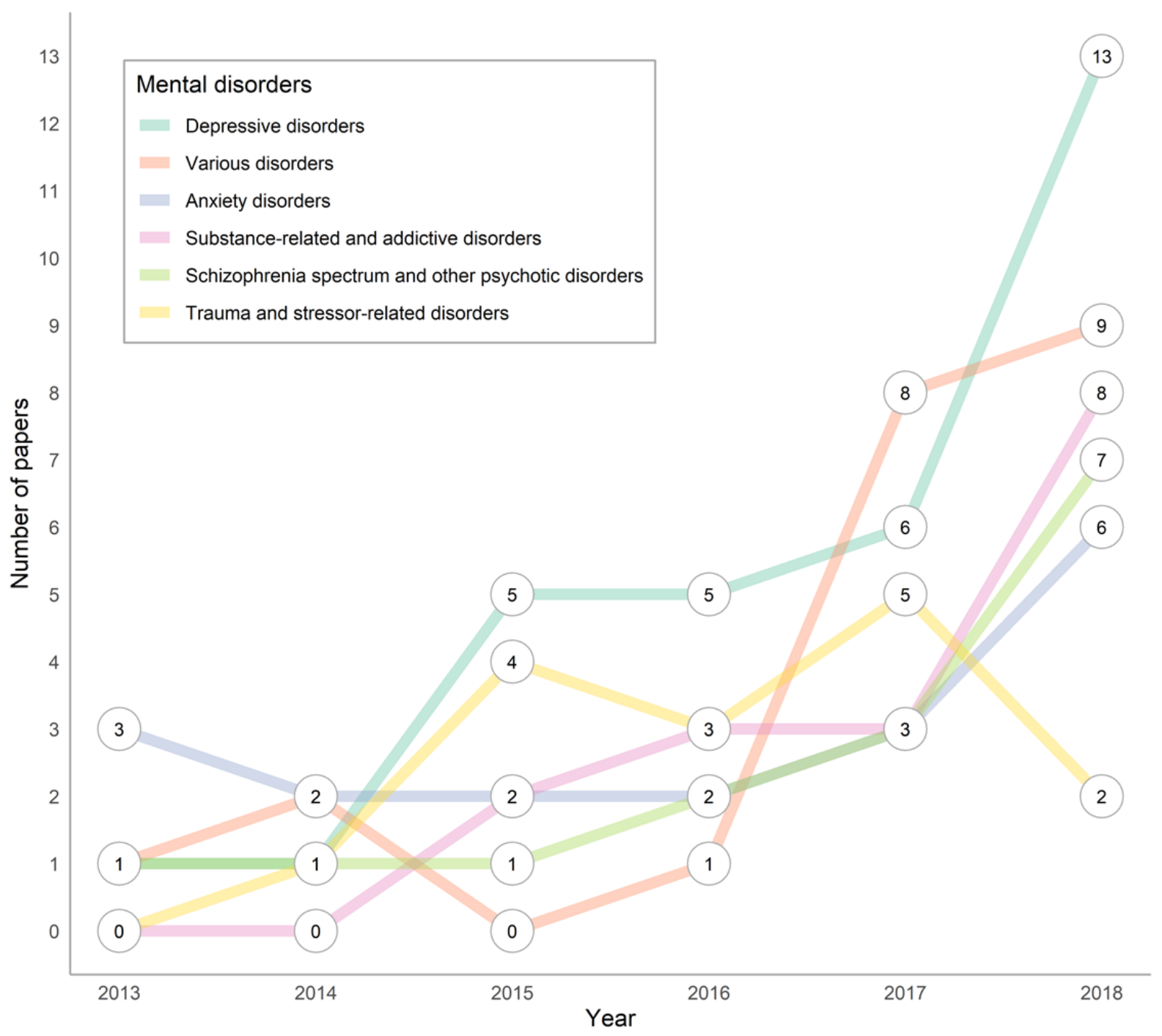

\section{Relation Between Assessment Type and Mental Disorder}

In Figure 3, we observe multiple effect assessments for all top six disorders, except for schizophrenia spectrum and other psychotic disorders $(0 / 15,0 \%)$. The depressive and anxiety disorders are relatively well studied for effect assessment; $19 \%$ $(6 / 31)$ and $28 \%(5 / 18)$ of assessments pertain to effect, respectively. On the other hand, effect is assessed only marginally for trauma and stressor-related disorder (13.3\%), substance-related and addictive disorder (12\%, 2/16), and various disorders $(9 \%, 2 / 21)$. For less addressed disorders (ie, not in the top six), we only see one or no effect assessment.

Regarding other types of assessment, no clear patterns can be observed, and we fall back to individual observations. Remarkable are the high number of mixed assessments for trauma and stressor-related disorders $(47 \%, 7 / 15)$ and to a lesser extent depressive disorders (39\%, 12/31); the low number of pure usability/UX assessments for anxiety disorders (5\%, $1 / 18)$, substance-related and addictive disorders $(6 \%, 1 / 16)$, and depressive disorders $(13 \%, 4 / 31)$; and the large number of articles without any assessment for anxiety disorders (44\%, $8 / 18$ ), which contrasts the high number of effect assessments.

\section{Coverage of Technical Features Per Mental Disorder}

Figure 5 plots the technology-related dimensions, namely, software features implemented by the studied apps (in orange), the utilized built-in sensors (in green), and analytics (in blue), vs the type of mental disorders. In doing so, the figure shows to which extent, and for which disorder(s), the state of the art is leveraging hardware- and/or software-related smartphone capabilities. Within each technology-related dimension ( $\mathrm{X}$ axis), features are ranked by their decreasing popularity over all mental disorders (left-right; occurrence count is shown at the top of each column); mental disorders (Y axis) are similarly ordered by decreasing popularity in literature (bottom-up). 
Figure 5. Bubble plot representing technology-related dimensions (software features—orange; built-in sensors—green; analytics—blue) vs mental disorders. Bubble size corresponds with the number of articles.

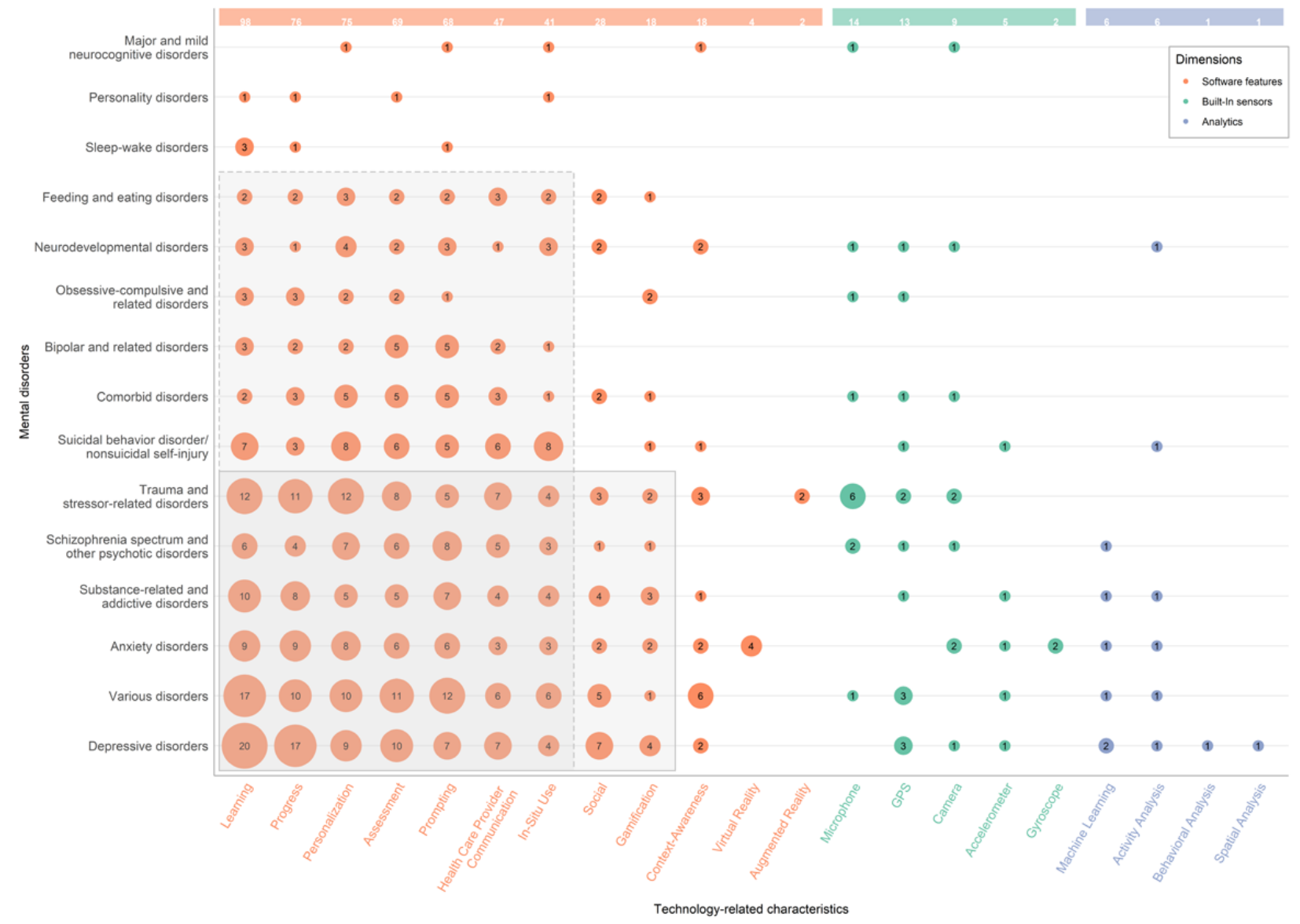

We note that larger bubbles tend to be concentrated at the bottom of the graph, as the most popular mental disorders have a higher number of articles, which also tend to cover more varied technical dimensions. The $7 \times 12$ vertical rectangle illustrates the top seven software features that are being leveraged for the majority of mental disorders (ie, 12 out of 15). These features are mostly related to intervention-specific features, such as learning and in situ use, and communication features such as prompting. The $9 \times 6$ rectangle shows nine software features that have full coverage for the top six mental disorders; it also includes social and gamification features. Regarding the delivery paradigm, virtual and augmented realities are each leveraged for only one mental disorder. Finally, regarding built-in sensors and analytics, we observe a much lower and dispersed coverage without clear patterns (especially for analytics). GPS stands out, with a relatively wide spread over mental disorders (ie, 9 out of 15).

\section{Concrete Studies Per Mental Disorder and App Name}

For the benefit of the research community, Table 2 lists the concrete studies (by app name, when available; if the app name was not found, we put N/A) per mental disorder. Apps that are the subject of multiple studies are shown in italics. On the one hand, it can be observed that, independent of the mental disorder, most studies utilized a custom-made app, which was not being assessed in other studies. On the other hand, this implies that there exists a wide variety of apps, even for the same mental disorder. Remarkably, for trauma and stressor-related disorders, most apps were assessed in multiple studies. Highlighting some interesting cases, Koroko-App (depressive disorders) is an app that was rigorously tested both for effect and usability/UX; a study protocol was published, followed by two RCTs assessing effect and usability/UX issues. Other apps, such as post-traumatic stress disorder coach and Simply Yoga (trauma and stressor-related disorders), combine RCTs with other type(s) of assessments for effect and usability/UX. Some apps such as the Blue Ice app (suicidal behavior disorders/nonsuicidal self-injury) published assessments using non-RCT designs. 
Table 2. Apps and studies grouped by mental disorder (apps covered in multiple publications are in italics).

\begin{tabular}{|c|c|}
\hline Mental disorder & References by app \\
\hline $\begin{array}{l}\text { Major and mild neurocognitive disor- } \\
\text { ders }\end{array}$ & Rico $[36]$ \\
\hline Personality disorders & EMOTEO [37] \\
\hline Sleep-wake disorders & Sleepcare [38], SleepIO $[39,40]$ \\
\hline Feeding and eating disorders & Jorvie [41], Student Bodies-Eating Disorders [42], Recovery Record [43,44] \\
\hline Neurodevelopmental disorders & iCanLearn [45], LifePal [46], My MFG [47], TimeOut [48] \\
\hline $\begin{array}{l}\text { Obsessive-compulsive and related } \\
\text { disorders }\end{array}$ & $\begin{array}{l}\text { Geo-Feedback App [49], GGOC [50], Live OCD Free [51], Mayo Clinic Anxiety Coach [52], RAW HAND } \\
\text { [53] }\end{array}$ \\
\hline Bipolar and related disorders & MyT [54], PRISM [55], SIMPLe [56-59] \\
\hline Comorbid disorders & $\begin{array}{l}\text { CASA-CHESS [60], Enuresis Trainer [61], Learn To Quit [62], SMI-CM [63], Stay Quit Coach [64], Stop- } \\
\text { Cannabis [65], N/A }{ }^{\text {a }}[66]\end{array}$ \\
\hline $\begin{array}{l}\text { Suicidal behavior disorder/nonsuici- } \\
\text { dal self-injury }\end{array}$ & $\begin{array}{l}\text { BackUp; mEMA [67], BeyondNow [68], BRITE [69], iBobbly [70], Virtual Hope Box (VHB) [71,72], N/A } \\
{[73,74], \text { Blue Ice [75-77] }}\end{array}$ \\
\hline Trauma and stressor-related disorders & $\begin{array}{l}\text { RELAX [78], N/A [79], Life Armor; PE Coach; Positive Activity Jackpot; Eventful; Tactical Breather; VHB; } \\
\text { Daily Yoga; Simply Yoga [79,80],PE Coach [81-84], PTSD Coach [85-91] }\end{array}$ \\
\hline $\begin{array}{l}\text { Schizophrenia spectrum and other } \\
\text { psychotic disorders }\end{array}$ & $\begin{array}{l}\text { iCOPE [92], MindFrame [93], movisenseXS [94], RealLife Exp [95], SlowMo [96], TechCare [97], Temstem } \\
\text { [98], Actissist [99,100], FOCUS [101,102], Heal Your Mind [103], PRIME [104,105] }\end{array}$ \\
\hline $\begin{array}{l}\text { Substance-related and addictive disor- } \\
\text { ders }\end{array}$ & $\begin{array}{l}\text { Drink Less [106], Fit\&Sobber [107], Mind the Moment [108], S-Health [109], SEVA [110], SmartQuit [111], } \\
\text { Smoke Mind [112], Social-Local-Mobile [113], A-CHESS [114,115], CET App [116,117], Kick.it [118,119], } \\
\text { Smart-T [120,121] }\end{array}$ \\
\hline Anxiety disorders & $\begin{array}{l}\text { Agoraphobia Free; Stress Free [122], Ångesthjälpen [123], AnxietyCoach [124], CBT Assistant [125], Chal- } \\
\text { lenger [126], Lantern [127], PsychAssist [128], Public Speech Trainer (PST) [129], SmartCAT [130], GET.ON } \\
P A P P \text { [131,132], N/A [133-139] }\end{array}$ \\
\hline Various disorders & $\begin{array}{l}\text { ACT Daily APP [140], FOCUS [141], Headspace [142], iBobbly [143], iCare-stress [144], IntelliCare Suite } \\
\text { [145], MoodMission [146], MoodTrainer [147], myCompass [148], PeerTECH App [149], Pocket Skills [150], } \\
\text { Sinasprite [151], SmartCAT [152], SPIRIT [153], The Moment [154], TODAY! [155], Wellframe [156], } \\
\text { WellWave [157], N/A [149], WorkingWell [158,159] }\end{array}$ \\
\hline Depressive disorders & $\begin{array}{l}\text { 7Cups [160], Be Good to Yourself [18], BlueWatch [161], Dcombat [162], Get Happy Program [163], HeadGear } \\
\text { [164], iCare Prevent [165], MedLink [166], Mobile Sensing and Support [167], MoodHacker [168], Moodivate } \\
\text { [169], MyGamePlan [170], PRIME-D [171], Push-D [172], SocioEmpathy [173], SPSRS [174], SuperBetter } \\
\text { [175], The Sound Advice [176], Thought Challenger [177], TODAC [178], Kokoro-App [179-181], N/A } \\
\text { [19,80,182-187] }\end{array}$ \\
\hline
\end{tabular}

${ }^{\mathrm{a} N} / \mathrm{A}$ : app name not available/not mentioned.

\section{Overview of Randomized Controlled Trial Assessments}

In Multimedia Appendix 3, we provide a comprehensive table with key variables of (pilot) RCT studies, including their main characteristics and results. We found a total of 32 rigorous assessment designs, with 7 pilot RCTs (22\%) and 25 RCTs $(78 \%)$. Below, we discuss the psychotherapy approaches (ie, treatment modalities) found in these assessments, temporal evolution of assessment types in RCTs, and notable observations on covered mental disorders.

Regarding approaches to psychotherapy, we found that $80.4 \%$ (127/158) of all included studies follow a cognitive behavioral therapy (CBT) psychological framework; $21.3 \%$ (27/127) of these additionally include third wave therapy techniques such as mindfulness or acceptance, or commitment therapy techniques. There are 13 apps fully based on a third wave therapy. Two apps are based on behavioral activation and physical activity. For the remaining mobile apps, no information regarding their psychological framework was reported in the article. When specifically considering the pilot RCT and the RCT studies, we observed the same trend: the majority is based on the CBT psychological framework, followed by studies which combine CBT with third wave therapy techniques. When looking at the overall temporal evolution of RCT studies, we noticed an even spread of combined effect and usability/UX evaluations over time. For effect studies, however, we observed that the majority took place in the last 2 years.

The most commonly addressed disorders by RCT studies were depressive disorders $(9 / 25,36 \%$ of the RCT studies). The majority of these studies showed that participants who received intervention apps significantly improved their symptoms (depression, anxiety, etc) compared with the waiting list $[18,175]$, alternative care [168], or control conditions [178,180]. Furthermore, studies with follow-ups showed that the treatment benefits were maintained $[168,178]$. One of the RCTs compared an intervention app with treatment as usual (ie, therapist); the results showed that, at posttreatment, the clinical variables did not differ between groups [186]. Another study compared two 
different apps, each featuring a different approach to psychotherapy (behavioral activation and mindfulness); the results showed that both apps were useful and did not differ significantly from one another [157]. The second most addressed disorder involved anxiety disorders $(4 / 25,16 \%$ of the RCT studies). Here, the results showed the same trend as for depressive disorders; participants who received intervention apps improved their symptoms significantly compared with the waiting list [123,126,139]. Furthermore, in studies with follow-ups, treatment benefits were maintained [126,139]. One of the studies compared two different intervention apps with different intervention targets, that is, agoraphobia vs general anxiety symptoms, for managing agoraphobia [122]. The results showed reductions in symptom severity over time that was statistically significant without differences between both apps

For schizophrenia spectrum and other psychotic disorders (3/25, $12 \%$ of the RCT studies), we found that 2 RCTs used the same app [104,105]. Results showed significant improvements in clinical symptoms posttrial compared with the waiting list, and also good acceptability [104,105]. A third app also showed positive results at posttreatment [100]. For substance-related and addictive disorders, we found one RCT; the study found improvements in alcohol outcomes for the participants [106]. Several other disorders were also only covered by one RCT. In case of sleep-wake disorders, the intervention app produced significant improvements in insomnia severity and sleep efficiency compared with the waiting list [38]. For suicidal behavior disorder/nonsuicidal self-injury disorders, the intervention app reported a significantly improved ability to cope with unpleasant emotions and thoughts compared with the control group [71]. In case of bipolar and related disorders, participants in the intervention app group showed significantly greater reductions in depressive symptoms [55]. For trauma and stressor-related disorders, RCT studies showed slightly less promising results. Usage of an intervention app did not result in significantly better outcomes compared with other active control conditions [79]; still, outcomes were better when compared with the waiting list condition [85].

\section{Discussion}

\section{Principal Findings}

In general, we infer a growing interest in utilizing smartphone apps for delivering psychological treatments, with research increasing from only a few (7) articles in 2013 to an order of magnitude more (60) in 2018. This is a promising trend, as these apps can complement therapist-led psychological treatments and, hence, increase their efficacy and availability. When delegating (part of) psychological treatment to smartphone-based interventions, the need for face-to-face sessions and manual follow-up is decreased, which, in turn, lowers costs and reduces waiting lists in the public health system. According to the mental health workforce breakdown (by the World Health Organization region), there are only 4.6 psychologists per 100,000 inhabitants in Europe [188]. For Spain, studies have reported wait times of more than 45 days before the first psychological assistance by a clinical psychologist or psychiatrist [188], and a frequency of face-to-face sessions of around once a month [189]. Moreover, leveraging smartphones' capabilities enables ecological momentary interventions (EMI), whereby patients are able to access psychological care when and where they need it most, in their natural environment and daily routines [190-192]. Below, we discuss our concrete observations on the assessment types of included studies, coverage of mental disorders, and technical features.

\section{Evolution of Research and Types of Assessment}

It is a promising sign that overall, the number of articles with some sort of assessment is slowly increasing. Furthermore, we observe that proportionally, there is a much higher number of studies with an evaluation of only usability/UX, compared with only effect. Usability factors have been widely recognized as key factors to enhance the acceptance of information and communication technologies (ICT) tools; on the basis of the technology acceptance model, authors have suggested that the intention to use a product in the future is strongly correlated with its ease of use [193,194]. Hence, initial efforts to research and ensure the usability of new ICT tools are essential. At the same time, we observe an overall much lower number (less than half compared with usability/UX) of studies that explicitly assesses the effect of smartphone interventions on clinical symptomatology (despite a peak in 2017). Yet, it is specifically this type of studies, focusing on the (long-term) clinical effects of the intervention, that are needed to demonstrate efficacy, and increase therapists' and patients' trust in smartphone-based interventions.

Moreover, RCTs, which are considered the gold standard of experiment design in mental health (and medicine in general), are only minimally represented in the literature $(22 / 158,15.8 \%$ of articles overall). Among them, we see an even spread of combined effect and usability/UX evaluations over time; for studies specifically focusing on effect, however, the majority took place in the last 2 years (with a peak in 2017). This is a promising sign, although there are still relatively few effect studies (see Multimedia Appendix 3). Furthermore, the most commonly addressed disorders using the RCT methodology are depressive disorders, followed by anxiety disorders. It is, thus, important to carry out more RCTs to prove mental health apps' efficacy in treating other mental disorders, and to study the satisfaction and experience of the patients using these apps. Moreover, to draw rigorous and trustworthy conclusions on the clinical efficacy of smartphone apps, more long-term RCT studies will be needed (eg, to better measure the effects of attrition). Similarly, we observe a distinct lack of cross-validation studies, with only a few apps having been studied in multiple articles $(19 / 138,13.8 \%)$. One could note that this phenomenon is correlated with the lack of rigorous long-term studies on smartphone interventions-a single, multiyear study would warrant multiple articles for a single smartphone intervention on study protocol, usability evaluation, and effect studies at multiple intervals. Particularly when utilizing novel technological features, rigorous assessment studies are needed to validate their potential for psychological interventions and encourage further research in the field. A stronger cooperation between research groups could increase the resources needed for such long-term psychological intervention studies. 


\section{Covered Mental Disorders}

To an extent, the coverage of mental disorders in the relevant literature seems to be in line with their real-world prevalence. This holds, in particular, for depressive and anxiety disorders, commonly called emotional disorders [195]; they (1) represent the first and third most covered disorders in the literature (we point out that various disorders include apps addressing multiples disorders, where depressive and anxiety disorders, in addition to serious mental illness, are most represented), with the research on depressive disorders being doubled in 2018 ; and (2) they are known to affect the most people worldwide. For mental disorders with highest prevalence among people [196,197], lifetime prevalence has been estimated at $28.8 \%$ for anxiety disorders, $20.8 \%$ for mood disorders (including $16.6 \%$ for depressive disorders, which are a mood disorder), $24.8 \%$ for impulse-control disorders, and $14.6 \%$ for substance use disorders. Estimated 12-month prevalence follows a similar trend: anxiety disorders are the most prevalent class with $18.1 \%$, followed by mood disorders with $9.5 \%$ (including $6.7 \%$ for depressive disorders), impulse-control disorders (8.9\%), and substance disorders $(3.8 \%)$ [196,197]. Hence, according to the psychological literature $[198,199]$, the three most prevalent mental disorders include anxiety, mood (including depressive disorders), and substance disorders. Indeed, these similarly make up our top four of most covered mental disorders in smartphone intervention studies. Depressive and anxiety disorders reduce a patient's psychosocial functioning and quality of life [198,200], and are associated with important personal, social, and economic repercussions [199,201]. Other ICT technologies for delivering psychological treatments, such as internet and Web-based programs, are also mostly focused on depressive and anxiety disorders [202,203]; this might also have had an influence on the proliferation of smartphone-based interventions. Although determining the underlying factor(s) behind the distribution of addressed mental disorders in the literature is certainly an interesting exercise, we consider this beyond the scope of this paper.

Beyond depressive and anxiety disorders, the literature is heavily focused on only a small number of disorders; six mental disorders account for approximately $73.4 \%$ (116/158) of research. On the other hand, more than half of the categories of mental disorders listed in DSM-5 (15) are fully excluded or very scarcely represented $(<3 \%)$. Clearly, there is an opportunity, as well as an acute need, to pay more attention to the whole breadth of mental disorders - that is, including those that are less prevalent-to help as many people as possible. Some of these less prevalent disorders, such as personality disorders, often have a higher severity that may lead to extreme consequences. For instance, borderline personality disorder affects only $2 \%$ to $6 \%$ of the population [204,205], but its mortality rate by suicide is one of the highest in the world among people with psychiatric disorders [206].

\section{Coverage of Technical Dimensions}

When looking at technical dimensions, more traditional software features (see $7 \times 12$ vertical rectangle in Figure 5) are much more utilized than the novel sensing or analytical capabilities of smartphones. One may argue that these top seven features, which involve intervention-specific features (eg, learning) and communication features (eg, prompting), do not offer a significant advancement over the prior state of the art. Indeed, many previous studies that leveraged (nonsmartphone) mobile phones supported learning by displaying psychoeducational content [56,58,140], receiving tips/reminders via SMS [47,149], using (bidirectional) SMS communication to perform (in situ) assessment [149], or telephone calls to health care providers $[75,81,145]$. Notwithstanding these observations, even this rather conservative transition to smartphones has enabled interventions that are out of reach for classic mobile phones. Research leveraging smartphones have exploited larger screen resolutions and multimedia capabilities to provide multimodal learning materials, using audio and video guides [122,184], pictures [71,75-77,87,154], audio [71,76,87], music [75-77], and video [71,77,174]. Some authors have leveraged the improved connectivity and ubiquity of smartphones to offer access to entire Web-based libraries of learning materials [152,184]; others utilize in-app prompting as intervention techniques, for example, sending reminders to use the app [76,85,116,178], motivational messages [47], or messages from the therapist [80,103]. We found studies that exploit the improved interactivity of smartphones to provide interactive quizzes for training skills and improved learning [62,152], assessments for panic attacks [133], suicidal intentions [143], symptoms of various disorders [54,120,121], and communication with therapists $[37,58,92,133]$ or other users $[79,104]$ through message/chat. Furthermore, aside from being better supported by smartphone capabilities, many of these psychological smartphone interventions are available at the touch of a button, instead of relying on receipt of SMS or phone calls.

That said, most studies still only scratch the surface of advanced smartphone capabilities. This is particularly apparent in the relatively low coverage of context awareness, that is, leveraging sensors to detect and react upon the current state of patients and their environments. We argue that such context awareness is a key ingredient of true EMI. Indeed, although EMI are meant to proactively issue suitable therapeutic interventions at the right time and place, most EMI studies consider smartphones merely as a tool for manually accessing interventions, or receiving predefined interventions at set time intervals, at any moment and place. We found a very limited number of smartphone-based studies leveraging external sensors for recording physiological parameters: measuring heart rate for detecting physiological arousal in the context of anger management [78], for instance. Similarly, we found very low coverage of analytics-based studies that could support advanced context awareness, for example, learning and assessing mental states based on physiological, environment, activity, and/or behavioral contexts. In our opinion, studies that progressively use internal and/or external smartphone sensors, possibly combined with advanced analytics, are a useful step toward realizing the full potential of EMI, where relevant events are detected through analysis of sensor readings, and acted upon by triggering suitable, personalized interventions when they are needed. The general hesitance toward context-aware EMI could be explained by the lack of validated computerized psychological models for assessing mental states based on patient context (including physiological, environment, and activity factors), as well as the need to 
combine technologically advanced solutions (ie, use of sensors, context awareness, and analytics).

Through their improved modalities (screen and sound), interactivity, and computational resources, smartphones enable novel intervention delivery paradigms, including virtual and augmented realities. However, these have found very limited coverage in the literature. We found a few individual studies, for example, utilizing a mobile VR system to help patients coping with agoraphobia by guiding an avatar through real-life simulations in a game-based setting [122]. Beyond exposure-type therapies, Repetto et al [137] utilized VR techniques to cope with generalized anxiety disorders, leveraging biofeedback to regulate features of the virtual world (eg, current heart rate). As mentioned before, the seeming lack of nontraditional intervention methods may be because of the lack of validated psychological models for supplying evidence-based VR or augmented reality, and/or the technical difficulty of novel delivery paradigms.

Given the lack of studies on these topics, we believe that there lies a huge potential for future research in utilizing technologically advanced solutions (ie, sensors, context awareness, and alternative delivery paradigms) to deliver smartphone-based psychological interventions tailored to the patient's current health context.

\section{Barriers to Implementation and Patient Risks}

Despite our advocation for further research in the utilization of smartphone features to advance treatments for mental disorders, we note that technological innovation should not constitute a goal in itself. It must provide a distinct advantage toward patient care, such as improved mental health care access, that is, a broader reach and lower barriers; increased assessment frequency and accuracy; lower cost; improved efficacy; and immediate access to care, when and where the patient needs it most. These intended benefits must be balanced with possible adverse effects, and the use of treatment modalities, including advanced technical features, needs to be carefully contemplated.

Here, we point out possible risks and barriers to implementation of smartphone-based interventions. The lack of research evidence on the effectiveness of mobile health apps is likely the most important issue to consider [207,208]. As shown in Table 1 , only a limited number of smartphone apps are validated using an RCT, and we observed a distinct lack of cross-validation studies, with only a few apps having been assessed in multiple studies. We further point out that this analysis only covers apps presented in the literature and not the many thousands of other, nonvalidated apps in popular app stores. There is a clear risk in using nonvalidated apps, as there is no evidence that they have any therapeutic effect, and they may even worsen the patient's condition. For example, Baron et al [209] noted that low-accuracy sleep trackers to self-diagnose sleep disturbances caused patients to be overly concerned on getting the perfect sleep (orthosomnia), which may have exacerbated their insomnia.

The ability to protect the privacy and confidentiality of patient information is pivotal as well [207,210-212] and may form a barrier to adoption. Many health-related apps collect a large amount of demographic, medical, and lifestyle information, as well as data on users' daily routines and practices [213]. Some apps have even been found to collect user data unrelated to the app's purpose [211]. Despite the importance of privacy with respect to (mental) health data, several researchers have found that a significant portion (31\%-49\%) of studied mental health apps does not include a privacy policy [210,214]. Collected information may be distributed to (third-party) services for storage and analysis. Moreover, unregulated apps may even pass on this information to unidentified parties, for example, for advertising purposes [210,211]. In a study of depression and smoking cessation mobile apps, it was observed that the majority $(81 \%)$ of the studied apps transmitted data for advertising and marketing purposes, but only $59 \%$ of the apps disclosed this in their privacy policy [210]. In all the aforementioned cases, there is a risk that personal data are being transmitted over insecure network connections [215,216]. Furthermore, there is the possibility of loss, theft, or malfunction of the mobile device [5], or cybercriminals specifically targeting health information [207], all of which could result in the loss of sensitive data.

Toward addressing these two issues, some authors suggest that mental health professionals should screen the apps they recommend for privacy issues [217]; however, this does not seem like a feasible or robust solution. Olff [218] proposed a disclaimer for apps that have not been validated. Taking it one step further, certification processes for mobile (mental) health apps have recently been instigated in the European Union (EU) and the United States, even though they do not apply to all apps. Under the 2017 EU Medical Device Regulation [219], mobile apps with a medical intended purpose require a CE marking. Devices (apps) may be differently classified depending on the purpose and risk they pose, yielding more or less stringent regulations regarding quality, control, or development process. The EU General Data Protection Regulation [220] has furthermore motivated a number of app developers to improve transparency on privacy policy, although confusion remains on its applicability outside the EU [211]. Similarly, in the United States, the Food and Drug Administration policy for mobile medical apps [221] stipulates that any software that is utilized for the diagnosis of disease or other conditions, or the cure, mitigation, treatment, or prevention of disease, constitutes a medical device, regardless of the platform on which it is run (eg, desktop or mobile). The applicable regulations depend on the particular functionality. Given the recency of these (updated) regulations, their rate of adoption and effects on efficacy, safety, privacy, and usability of mHealth apps remain to be seen, and we expect the regulations to be further clarified, refined, and extended in scope in the future.

Further barriers to implementation include a lack of sufficient general, digital, and health literacy levels [207] and a digital divide [222], the view and attitude of practitioners and patients toward the use of mobile mental health interventions [223,224], availability and awareness of evidence-based apps [225], economic and other associated costs [226], and user acceptance and usability [226]. For further elaboration on barriers and facilitators to implementation of mental health care apps, we refer the readers to Lipschitz et al [225] and Simblett et al [226]. 


\section{Recommendations for the Research Community}

In line with our findings, we propose four recommendations for the research community to further develop and advance the field of smartphone-based psychological interventions:

- Attention for less covered disorders: The majority of research (approximately 73\%) pertains to the top six covered mental disorders, four of which coincide with highly prevalent mental disorders. On the other hand, more than half of the DSM-5 recognized mental disorders are not or very scarcely covered. We call upon the research community to invest into covering the full breadth of mental disorders.

- Attention for advanced technical and software-based solutions: Many smartphone-based psychological interventions merely translate traditional and electronic health (eHealth) solutions to smartphones; that is, these interventions do not fully exploit their capabilities. Concretely, the use of sensors and corresponding context awareness, particularly to promote EMI, the exploration of alternative delivery paradigms such as virtual or augmented reality, and more advanced analytical methods are scarcely investigated. We call upon the research community to explore beyond traditional strategies, toward leveraging advanced technological features to improve mHealth interventions.

- Multidisciplinary approaches: To fully exploit the smartphone's capability as a pervasive, ubiquitously connected, sensor-packed computing platform to deliver innovative, real-time, and in situ psychological interventions, both the domain knowledge of psychologists and the technical expertise of computer scientists are needed. Hence, we call for multidisciplinary collaborations as to not let technical difficulties, or lack of psychological knowledge on mental disorders, hinder advances and novelties in the field.

- Validation toward effect: Although we uncovered, at least in absolute numbers, a slight increase in effect validations and RCT-based effect assessments during the last 2 years combined, they are still underrepresented (particularly RCTs). Hence, there exists a need to rigorously validate smartphone-based psychological treatments for effect. Especially when utilizing advanced technical features (eg, context awareness, analytics, and alternative delivery paradigms), effect validation may increase trust and spark further research in such novel types of interventions. We call upon the research community to augment efforts in rigorous effect assessment, to allow transfer of research into practice.

Despite our call for research in technical innovation and its broader applicability and validation, we note that the eventual use of such advanced technical features - or any technological aid in psychological interventions for that matter-needs to be carefully balanced with the characteristics and needs of the individual patient.

\section{Strengths and Limitations}

The main strength and novelty of this study is that it explored and summarized, considering a wide range of technical characteristics, the current state of the art in smartphone-based interventions for mental disorders. We hereby provide a broad overview of the field (1) covering the full spectrum of mental disorders as classified in the latest version of DSM, rather than focusing on a specific mental illness as done in previous studies; and (2) exposing technical features used to realize smartphone-based treatments. Consequently, this contribution is highly innovative as a synergetic study targeting mental health research and recent developments in mobile sensing and computing. Further strengths of this study include the use of four different bibliographic sources for a comprehensive coverage of the research and literature, and the methodological process based on pairs of multidisciplinary researchers for the selection, validation, and classification of the literature.

As any systematic study, search term specification may lack other relevant terms not considered by the authors, and searches only covered the literature published in English. Therefore, there always exists a risk to not fully identify all relevant studies. Classification of studies may also be prone to error. To reduce this risk, we used pairs of researchers from different disciplines with a requirement of interrater agreement.

\section{Conclusions}

We presented a comprehensive systematic review of the state of the art in smartphone-based psychological interventions, with a synergetic focus on psychology-related issues, such as mental disorders and type of assessment, as well as technological features, such as software features and device sensors. Our results show a rapid increase over recent years in the number of psychological interventions for various mental disorders using smartphone-based apps. It captures how depressive and anxiety disorders are primarily covered, in line with their real-world prevalence. The top six of mental disorders together account for approximately three-quarters of coverage in the literature, while over half are not or very scarcely covered. This implies the need for further research on smartphone interventions for the full breadth of mental disorders to help as many affected people as possible. On the technical side, the review highlights a group of software features related to intervention (eg, learning and in situ use) and communication (eg, prompting) deployed in smartphone interventions that mostly mimic more traditional mobile phone and eHealth solutions. More innovative use of smartphones' capabilities, such as sensing, alternative delivery paradigms, and advanced analytics, are only scarcely present in the literature, despite their potential for advancing solutions such as EMI. With regard to studies including an assessment, we found that there is an overall slow proportional increase, with significantly more usability/UX compared with effect studies. RCT studies are still a small minority. They mostly deal with depressive and anxiety disorders. Over the last 2 years, there are promising yet inconclusive signs of more effect studies. 


\section{Acknowledgments}

IM was funded by the Spanish Ministry of Education, Culture and Sports (grant reference FPU14/00020). CG and SC were funded by the Ramon y Cajal Programme of the Spanish government (grant references RYC-2014-16913 and RYC-2014-16606 respectively). LD was funded by the Conselleria de Educación, Investigación, Cultura y Deporte ORDRE 86/2016, de 21 de desembre [2016/10396] (grant reference ACIF/2017/181). This study was supported by the SYMPTOMS project of the Programa Estatal de I+D+i Orientada a los Retos de la Sociedad of the Spanish government (grant number RTI2018-099939-B-I00) and by the UJI-A2016-14 Program, Project 16I336.01/1 (Universitat Jaume I).

\section{Conflicts of Interest}

None declared.

\section{Multimedia Appendix 1}

Keywords.

[DOCX File, 14 KB-Multimedia Appendix 1]

\section{Multimedia Appendix 2}

Search queries.

[DOCX File, 15 KB-Multimedia Appendix 2]

\section{Multimedia Appendix 3}

Key variables for randomized controlled trials or pilot randomized controlled trial studies.

[DOCX File, $41 \mathrm{~KB}-$ Multimedia Appendix 3]

\section{References}

1. Statista. 2019. Number of Smartphone Users Worldwide From 2016 to 2021 (in billions) URL: https://www.statista.com/ statistics/330695/number-of-smartphone-users-worldwide/ [accessed 2019-09-01]

2. Taylor K, Silver L. Pew Research Center. 2019. Smartphone Ownership Is Growing Rapidly Around the World, but Not Always Equally URL: https://www.pewglobal.org/wp-content/uploads/sites/2/2019/02/ Pew-Research-Center Global-Technology-Use-2018 2019-02-05.pdf [accessed 2019-09-01]

3. Clement J. Statista. Mobile App Usage - Statistics \& Facts URL: https://www.statista.com/topics/1002/mobile-app-usage/ [accessed 2018-03-09]

4. Mosa AS, Yoo I, Sheets L. A systematic review of healthcare applications for smartphones. BMC Med Inform Decis Mak 2012 Jul 10;12:67 [FREE Full text] [doi: 10.1186/1472-6947-12-67] [Medline: 22781312]

5. Luxton DD, McCann RA, Bush NE, Mishkind MC, Reger GM. mHealth for mental health: integrating smartphone technology in behavioral healthcare. Prof Psychol 2011;42(6):505-512. [doi: 10.1037/a0024485]

6. Koch S. Home telehealth--current state and future trends. Int J Med Inform 2006 Aug;75(8):565-576. [doi: $\underline{\text { 10.1016/j.ijmedinf.2005.09.002] [Medline: 16298545] }}$

7. Krishna S, Boren SA, Balas EA. Healthcare via cell phones: a systematic review. Telemed J E Health 2009 Apr;15(3):231-240. [doi: 10.1089/tmj.2008.0099] [Medline: 19382860]

8. Bert F, Giacometti M, Gualano MR, Siliquini R. Smartphones and health promotion: a review of the evidence. J Med Syst 2014 Jan;38(1):9995. [doi: 10.1007/s10916-013-9995-7] [Medline: 24346929]

9. Cunningham PJ. Beyond parity: primary care physicians' perspectives on access to mental health care. Health Aff (Millwood) 2009;28(3):w490-w501. [doi: 10.1377/hlthaff.28.3.w490] [Medline: 19366722]

10. Huxley CJ, Atherton H, Watkins JA, Griffiths F. Digital communication between clinician and patient and the impact on marginalised groups: a realist review in general practice. Br J Gen Pract 2015 Dec;65(641):e813-e821 [FREE Full text] [doi: 10.3399/bjgp15X687853] [Medline: 26622034]

11. Rathbone AL, Prescott J. The use of mobile apps and SMS messaging as physical and mental health interventions: systematic review. J Med Internet Res 2017 Aug 24;19(8):e295 [FREE Full text] [doi: 10.2196/jmir.7740] [Medline: 28838887]

12. Pepin R, Segal DL, Coolidge FL. Intrinsic and extrinsic barriers to mental health care among community-dwelling younger and older adults. Aging Ment Health 2009 Sep;13(5):769-777. [doi: 10.1080/13607860902918231] [Medline: 19882416]

13. Rowan K, McAlpine DD, Blewett LA. Access and cost barriers to mental health care, by insurance status, $1999-2010$. Health Aff (Millwood) 2013 Oct;32(10):1723-1730 [FREE Full text] [doi: 10.1377/hlthaff.2013.0133] [Medline: 24101061]

14. Twomey C, O'Reilly G, Meyer B. Effectiveness of an individually-tailored computerised CBT programme (Deprexis) for depression: A meta-analysis. Psychiatry Res 2017 Oct;256:371-377. [doi: 10.1016/j.psychres.2017.06.081] [Medline: 28686935] 
15. Trautmann S, Rehm J, Wittchen HU. The economic costs of mental disorders: Do our societies react appropriately to the burden of mental disorders? EMBO Rep 2016 Sep;17(9):1245-1249 [FREE Full text] [doi: 10.15252/embr.201642951] [Medline: 27491723]

16. Bagalman E, Cornell AS. Federation Of American Scientists. 2018 Jan 19. Prevalence of Mental Illness in the United States: Data Sources and Estimates URL: https://fas.org/sgp/crs/misc/R43047.pdf [accessed 2020-02-05]

17. Firth J, Torous J, Nicholas J, Carney R, Rosenbaum S, Sarris J. Can smartphone mental health interventions reduce symptoms of anxiety? A meta-analysis of randomized controlled trials. J Affect Disord 2017 Aug 15;218:15-22 [FREE Full text] [doi: 10.1016/j.jad.2017.04.046] [Medline: 28456072]

18. Lüdtke T, Pult L, Schröder J, Moritz S, Bücker L. A randomized controlled trial on a smartphone self-help application (Be Good to Yourself) to reduce depressive symptoms. Psychiatry Res 2018 Nov;269:753-762. [doi: 10.1016/j.psychres.2018.08.113] [Medline: 30273901]

19. Ly KH, Topooco N, Cederlund H, Wallin A, Bergström J, Molander O, et al. Smartphone-supported versus full behavioural activation for depression: a randomised controlled trial. PLoS One 2015;10(5):e0126559 [FREE Full text] [doi: 10.1371/journal.pone.0126559] [Medline: 26010890]

20. Proudfoot J, Parker G, Pavlovic DH, Manicavasagar V, Adler E, Whitton A. Community attitudes to the appropriation of mobile phones for monitoring and managing depression, anxiety, and stress. J Med Internet Res 2010 Dec 19;12(5):e64 [FREE Full text] [doi: 10.2196/jmir.1475] [Medline: 21169174]

21. Andersson E, Steneby S, Karlsson K, Ljótsson B, Hedman E, Enander J, et al. Long-term efficacy of internet-based cognitive behavior therapy for obsessive-compulsive disorder with or without booster: a randomized controlled trial. Psychol Med 2014 Oct;44(13):2877-2887. [doi: 10.1017/S0033291714000543] [Medline: 25066102]

22. Marzano L, Bardill A, Fields B, Herd K, Veale D, Grey N, et al. The application of mHealth to mental health: opportunities and challenges. Lancet Psychiatry 2015 Oct;2(10):942-948. [doi: 10.1016/S2215-0366(15)00268-0] [Medline: 26462228]

23. Grist R, Porter J, Stallard P. Mental health mobile apps for preadolescents and adolescents: a systematic review. J Med Internet Res 2017 May 25;19(5):e176 [FREE Full text] [doi: 10.2196/jmir.7332] [Medline: 28546138]

24. Ehrenreich B, Righter B, Rocke DA, Dixon L, Himelhoch S. Are mobile phones and handheld computers being used to enhance delivery of psychiatric treatment? A systematic review. J Nerv Ment Dis 2011 Nov;199(11):886-891. [doi: 10.1097/NMD.0b013e3182349e90] [Medline: 22048142]

25. Donker T, Petrie K, Proudfoot J, Clarke J, Birch M, Christensen H. Smartphones for smarter delivery of mental health programs: a systematic review. J Med Internet Res 2013 Nov 15;15(11):e247 [FREE Full text] [doi: 10.2196/jmir.2791] [Medline: 24240579]

26. Naslund JA, Marsch LA, McHugo GJ, Bartels SJ. Emerging mHealth and eHealth interventions for serious mental illness: a review of the literature. J Ment Health 2015;24(5):321-332 [FREE Full text] [doi: 10.3109/09638237.2015.1019054] [Medline: 26017625]

27. Bateman DR, Srinivas B, Emmett TW, Schleyer TK, Holden RJ, Hendrie HC, et al. Categorizing health outcomes and efficacy of mHealth apps for persons with cognitive impairment: a systematic review. J Med Internet Res 2017 Aug 30;19(8):e301 [FREE Full text] [doi: 10.2196/jmir.7814] [Medline: 28855146]

28. Kazemi DM, Borsari B, Levine MJ, Li S, Lamberson KA, Matta LA. A systematic review of the mHealth interventions to prevent alcohol and substance abuse. J Health Commun 2017 May;22(5):413-432 [FREE Full text] [doi: 10.1080/10810730.2017.1303556] [Medline: 28394729]

29. Berrouiguet S, Baca-García E, Brandt S, Walter M, Courtet P. Fundamentals for future mobile-health (mHealth): a systematic review of mobile phone and web-based text messaging in mental health. J Med Internet Res 2016 Jun 10;18(6):e135 [FREE Full text] [doi: 10.2196/jmir.5066] [Medline: 27287668]

30. Free C, Phillips G, Felix L, Galli L, Patel V, Edwards P. The effectiveness of M-health technologies for improving health and health services: a systematic review protocol. BMC Res Notes 2010 Oct 6;3:250 [FRE Full text] [doi: 10.1186/1756-0500-3-250] [Medline: 20925916]

31. Payne HE, Lister C, West JH, Bernhardt JM. Behavioral functionality of mobile apps in health interventions: a systematic review of the literature. JMIR Mhealth Uhealth 2015 Feb 26;3(1):e20 [FREE Full text] [doi: 10.2196/mhealth.3335] [Medline: 25803705]

32. Liberati A, Altman DG, Tetzlaff J, Mulrow C, Gøtzsche PC, Ioannidis JP, et al. The PRISMA statement for reporting systematic reviews and meta-analyses of studies that evaluate healthcare interventions: explanation and elaboration. $\mathrm{Br}$ Med J 2009 Jul 21;339:b2700 [FREE Full text] [doi: 10.1136/bmj.b2700] [Medline: 19622552]

33. American Psychiatric Association. Diagnostic and Statistical Manual of Mental Disorders (DSM-5). Washington, DC: American Psychiatric Publishing; 2013.

34. International Organization for Standardization. 2010. ISO 9241-210:2010 Ergonomics of Human-System Interaction Part 210: Human-Centred Design for Interactive Systems URL: https://www.iso.org/standard/52075.html [accessed 2020-02-05]

35. Granell C, Bretón-López J, Casteleyn S, Castilla D, Díaz L, Mira A, et al. Zenodo. 2020 Jan 15. Reproducibility Package for 'Smartphone apps for the treatment of mental disorders: a systematic review' URL: https://doi.org/10.5281/zenodo. $\underline{3609267}$ [accessed 2020-02-05] 
36. Al-Asad RY, Al-Zuhair AJ, Esmacili SE. Smart Phone Based Facial and Text Recognition Application (RICO). In: Proceedings of the Iranian Conference on Electrical Engineering. 2018 Presented at: ICEE'18; May 8-10, 2018; Mashhad, Iran p. 125-129. [doi: 10.1109/ICEE.2018.8472658]

37. Prada P, Zamberg I, Bouillault G, Jimenez N, Zimmermann J, Hasler R, et al. EMOTEO: a smartphone application for monitoring and reducing aversive tension in borderline personality disorder patients, a pilot study. Perspect Psychiatr Care 2017 Oct;53(4):289-298. [doi: 10.1111/ppc.12178] [Medline: 27439663]

38. Horsch CH, Lancee J, Griffioen-Both F, Spruit S, Fitrianie S, Neerincx MA, et al. Mobile phone-delivered cognitive behavioral therapy for insomnia: a randomized waitlist controlled trial. J Med Internet Res 2017 Apr 11;19(4):e70 [FREE Full text] [doi: 10.2196/jmir.6524] [Medline: 28400355]

39. Espie CA, Luik AI, Cape J, Drake CL, Siriwardena AN, Ong JC, et al. Digital Cognitive Behavioural Therapy for Insomnia versus sleep hygiene education: the impact of improved sleep on functional health, quality of life and psychological well-being. Study protocol for a randomised controlled trial. Trials 2016 May 23;17(1):257 [FREE Full text] [doi: 10.1186/s13063-016-1364-7] [Medline: 27216112]

40. Kyle S, Hurry ME, Emsley R, Luik AI, Omlin X, Spiegelhalder K, et al. Effects of digital Cognitive Behavioural Therapy for Insomnia on cognitive function: study protocol for a randomised controlled trial. Trials 2017 Jun 17;18(1):281 [FREE Full text] [doi: 10.1186/s13063-017-2012-6] [Medline: 28623947]

41. Kolar D, Hammerle F, Jenetzky E, Huss M. Smartphone-Enhanced Low-Threshold Intervention for adolescents with Anorexia Nervosa (SELTIAN) waiting for outpatient psychotherapy: study protocol of a randomised controlled trial. BMJ Open 2017 Oct 22;7(10):e018049 [FREE Full text] [doi: 10.1136/bmjopen-2017-018049] [Medline: 29061627]

42. Nitsch M, Dimopoulos CN, Flaschberger E, Saffran K, Kruger JF, Garlock L, et al. A guided online and mobile self-help program for individuals with eating disorders: an iterative engagement and usability study. J Med Internet Res 2016 Jan 11;18(1):e7 [FREE Full text] [doi: 10.2196/jmir.4972] [Medline: 26753539]

43. Tregarthen JP, Lock J, Darcy AM. Development of a smartphone application for eating disorder self-monitoring. Int J Eat Disord 2015 Nov;48(7):972-982. [doi: 10.1002/eat.22386] [Medline: 26213130]

44. Lindgreen P, Lomborg K, Clausen L. Patient experiences using a self-monitoring app in eating disorder treatment: qualitative study. JMIR Mhealth Uhealth 2018 Jun 22;6(6):e10253 [FREE Full text] [doi: 10.2196/10253] [Medline: 29934285]

45. Zaffke A, Jain N, Johnson N, Ul Alam MA, Magiera M, Ahamed SI. iCanLearn: A Mobile Application for Creating Flashcards and Social Stories for Children with Autism. In: Proceedings of the International Conference on Smart Homes and Health Telematics. 2014 Presented at: ICOST'14; June 25-27, 2014; Denver, CO, USA p. 225-230 URL: https://doi. org/10.1007/978-3-319-14424-5 25 [doi: 10.1007/978-3-319-14424-5 25]

46. Skillen KL, Donnelly MP, Nugent CD, Booth N. LifePal: A Mobile Self-management Tool for Supporting Young People with Autism. In: Proceedings of the XIV Mediterranean Conference on Medical and Biological Engineering and Computing. 2016 Presented at: MEDICON'16; March 31-April 2, 2016; Paphos, Cyprus p. 1174-1179 URL: https://doi.org/10.1007/ 978-3-319-32703-7_227 [doi: 10.1007/978-3-319-32703-7_228]

47. Chacko A, Isham A, Cleek AF, McKay MM. Using mobile health technology to improve behavioral skill implementation through homework in evidence-based parenting intervention for disruptive behavior disorders in youth: study protocol for intervention development and evaluation. Pilot Feasibility Stud 2016;2:57 [FREE Full text] [doi: 10.1186/s40814-016-0097-4] [Medline: 27965873]

48. Flobak E, Jensen DA, Lundervold AJ, Nordgreen T, Chen LH, Guribye F. Towards Technology-Based Interventions for Improving Emotional and Cognitive Control. In: Proceedings of the Extended Abstracts of the 2018 CHI Conference on Human Factors in Computing Systems. 2018 Presented at: CHI EA'18; April 21-26, 2018; Montréal, QC, Canada. [doi: 10.1145/3170427.3188603]

49. Olbrich H, Stengler K, Olbrich S. Smartphone based Geo-Feedback in obsessive compulsive disorder as facilitatory intervention: a case report. J Obsessive Compuls Relat Disord 2016;8:75-78 [FREE Full text] [doi: 10.1016/j.jocrd.2016.01.001]

50. Pascual-Vera B, Roncero M, Doron G, Belloch A. Assisting relapse prevention in OCD using a novel mobile app-based intervention: a case report. Bull Menninger Clin 2018;82(4):390-406. [doi: 10.1521/bumc.2018.82.4.390] [Medline: $\underline{30589573]}$

51. Boisseau CL, Schwartzman CM, Lawton J, Mancebo MC. App-guided exposure and response prevention for obsessive compulsive disorder: an open pilot trial. Cogn Behav Ther 2017 Nov;46(6):447-458. [doi: 10.1080/16506073.2017.1321683] [Medline: 28565937]

52. Whiteside SP, Ale CM, Douglas KV, Tiede MS, Dammann JE. Case examples of enhancing pediatric OCD treatment with a smartphone application. Clin Case Stud 2014;13(1):80-94 [FREE Full text] [doi: 10.1177/1534650113504822]

53. Hong JS, Kim SM, Aboujaoude E, Han DH. Investigation of a mobile 'Serious Game' in the treatment of obsessive-compulsive disorder: a pilot study. Games Health J 2018 Oct;7(5):317-326. [doi: 10.1089/g4h.2017.0158] [Medline: 30129775]

54. Wenze SJ, Armey MF, Weinstock LM, Gaudiano BA, Miller IW. An open trial of a smartphone-assisted, adjunctive intervention to improve treatment adherence in bipolar disorder. J Psychiatr Pract 2016 Nov;22(6):492-504 [FREE Full text] [doi: 10.1097/PRA.0000000000000196] [Medline: 27824786] 
55. Depp CA, Ceglowski J, Wang VC, Yaghouti F, Mausbach BT, Thompson WK, et al. Augmenting psychoeducation with a mobile intervention for bipolar disorder: a randomized controlled trial. J Affect Disord 2015 Mar 15;174:23-30 [FREE Full text] [doi: $\underline{10.1016 / j . j a d .2014 .10 .053}$ ] [Medline: $\underline{25479050}$ ]

56. Hidalgo-Mazzei D, Reinares M, Mateu A, Juruena MF, Young AH, Pérez-Sola V, et al. Is a SIMPLe smartphone application capable of improving biological rhythms in bipolar disorder? J Affect Disord 2017 Dec 1;223:10-16. [doi: 10.1016/j.jad.2017.07.028] [Medline: 28711743]

57. Hidalgo-Mazzei D, Vieta E, Colom F. Self-Monitoring and Psychoeducation in Bipolar Patients with a Smart-phone application (SIMPLe) project: Preliminary results from a feasibility study. In: Proceedings of the 5th EAI International Conference on Wireless Mobile Communication and Healthcare. 2015 Presented at: MOBIHEALTH'15; October 14-16, 2015; London p. 227-230 URL: https://doi.org/10.4108/eai.14-10-2015.2261770 [doi: 10.4108/eai.14-10-2015.2261770]

58. Hidalgo-Mazzei D, Mateu A, Reinares M, Murru A, Del Mar Bonnín C, Varo C, et al. Psychoeducation in bipolar disorder with a SIMPLe smartphone application: feasibility, acceptability and satisfaction. J Affect Disord 2016 Aug;200:58-66. [doi: 10.1016/j.jad.2016.04.042] [Medline: 27128358]

59. Hidalgo-Mazzei D, Reinares M, Mateu A, Nikolova VL, Del Mar Bonnín C, Samalin L, et al. OpenSIMPLe: a real-world implementation feasibility study of a smartphone-based psychoeducation programme for bipolar disorder. J Affect Disord 2018 Dec 1;241:436-445. [doi: 10.1016/j.jad.2018.08.048] [Medline: 30145515]

60. Muroff J, Robinson W, Chassler D, López LM, Gaitan E, Lundgren L, et al. Use of a smartphone recovery tool for Latinos with co-occurring alcohol and other drug disorders and mental disorders. J Dual Diagn 2017;13(4):280-290. [doi: 10.1080/15504263.2017.1348649] [Medline: 28692420]

61. Tajima-Pozo K, Ruiz-Manrique G, Montañes F. Treating enuresis in a patient with ADHD: application of a novel behavioural modification therapy. BMJ Case Rep 2014 Jun 10;2014:pii: bcr2014203912 [FREE Full text] [doi: 10.1136/bcr-2014-203912] [Medline: 24916977]

62. Vilardaga R, Rizo J, Zeng E, Kientz JA, Ries R, Otis C, et al. User-centered design of learn to quit, a smoking cessation smartphone app for people with serious mental illness. JMIR Serious Games 2018 Jan 16;6(1):e2 [FREE Full text] [doi: 10.2196/games.8881] [Medline: 29339346]

63. Minami H, Brinkman HR, Nahvi S, Arnsten JH, Rivera-Mindt M, Wetter DW, et al. Rationale, design and pilot feasibility results of a smartphone-assisted, mindfulness-based intervention for smokers with mood disorders: Project mSMART MIND. Contemp Clin Trials 2018 Mar;66:36-44 [FREE Full text] [doi: 10.1016/j.cct.2017.12.014] [Medline: 29288740]

64. Herbst E, Pennington D, Kuhn E, McCaslin SE, Delucchi K, Batki SL, et al. Mobile technology for treatment augmentation in veteran smokers with posttraumatic stress disorder. Am J Prev Med 2018 Jan;54(1):124-128. [doi: 10.1016/j.amepre.2017.08.016] [Medline: 29074319]

65. Benarous X, Edel Y, Consoli A, Brunelle J, Etter J, Cohen D, et al. Ecological momentary assessment and smartphone application intervention in adolescents with substance use and comorbid severe psychiatric disorders: study protocol. Front Psychiatry 2016;7:157 [FREE Full text] [doi: 10.3389/fpsyt.2016.00157] [Medline: 27703435]

66. Matalenas LA, McLaughlin AC, Chen Y, Daughters SB. Developing a smartphone application for the life enhancement treatment for substance use (lets act): designing for motivation and feedback. Proc Hum Factors Ergon Soc Annu Meet 2015;59(1):1100-1104 [FREE Full text] [doi: 10.1177/1541931215591158]

67. Nuij C, van Ballegooijen W, Ruwaard J, de Beurs D, Mokkenstorm J, van Duijn E, et al. Smartphone-based safety planning and self-monitoring for suicidal patients: rationale and study protocol of the CASPAR (Continuous Assessment for Suicide Prevention And Research) study. Internet Interv 2018 Sep;13:16-23 [FREE Full text] [doi: 10.1016/j.invent.2018.04.005] [Medline: $\underline{30206514]}$

68. Melvin GA, Gresham D, Beaton S, Coles J, Tonge BJ, Gordon MS, et al. Evaluating the feasibility and effectiveness of an Australian safety planning smartphone application: a pilot study within a tertiary mental health service. Suicide Life Threat Behav 2019 Jun;49(3):846-858 [FREE Full text] [doi: 10.1111/sltb.12490] [Medline: 29999193]

69. Kennard BD, Goldstein T, Foxwell AA, McMakin DL, Wolfe K, Biernesser C, et al. As Safe as Possible (ASAP): a brief app-supported inpatient intervention to prevent postdischarge suicidal behavior in hospitalized, suicidal adolescents. Am J Psychiatry 2018 Sep 1;175(9):864-872 [FREE Full text] [doi: 10.1176/appi.ajp.2018.17101151] [Medline: $\underline{30021457]}$

70. Tighe J, Shand F, Ridani R, Mackinnon A, de La Mata N, Christensen H. Ibobbly mobile health intervention for suicide prevention in Australian Indigenous youth: a pilot randomised controlled trial. BMJ Open 2017 Jan 27;7(1):e013518 [FREE Full text] [doi: 10.1136/bmjopen-2016-013518] [Medline: 28132007]

71. Bush NE, Smolenski DJ, Denneson LM, Williams HB, Thomas EK, Dobscha SK. A Virtual Hope Box: randomized controlled trial of a smartphone app for emotional regulation and coping with distress. Psychiatr Serv $2017 \mathrm{Apr}$ 1;68(4):330-336. [doi: 10.1176/appi.ps.201600283] [Medline: 27842473]

72. Chen JI, Smolenski DJ, Dobscha SK, Bush NE, Denneson LM. Correlates of mental health smartphone application use among patients with suicidal ideation. J Technol Hum Serv 2018;36(4):191-207. [doi: 10.1080/15228835.2018.1502119]

73. Shand FL, Ridani R, Tighe J, Christensen H. The effectiveness of a suicide prevention app for indigenous Australian youths: study protocol for a randomized controlled trial. Trials 2013 Nov 20;14:396 [FREE Full text] [doi:

10.1186/1745-6215-14-396] [Medline: 24257410] 
74. O'Brien KH, LeCloux M, Ross A, Gironda C, Wharff EA. A pilot study of the acceptability and usability of a smartphone application intervention for suicidal adolescents and their parents. Arch Suicide Res 2017;21(2):254-264. [doi: 10.1080/13811118.2016.1182094] [Medline: 27136115]

75. Stallard P, Porter J, Grist R. Safety, acceptability, and use of a smartphone app, BlueIce, for young people who self-harm: protocol for an open Phase I trial. JMIR Res Protoc 2016 Nov 16;5(4):e217 [FREE Full text] [doi: 10.2196/resprot.6525] [Medline: 27852560]

76. Stallard P, Porter J, Grist R. A Smartphone App (BlueIce) for Young People Who Self-Harm: Open Phase 1 Pre-Post Trial. JMIR Mhealth Uhealth 2018 Jan 30;6(1):e32 [FREE Full text] [doi: 10.2196/mhealth.8917] [Medline: 29382632]

77. Grist R, Porter J, Stallard P. Acceptability, use, and safety of a mobile phone app (BlueIce) for young people who self-harm: qualitative study of service users' experience. JMIR Ment Health 2018 Feb 23;5(1):e16 [FREE Full text] [doi: 10.2196/mental.8779] [Medline: 29475823]

78. Morland LA, Niehaus J, Taft C, Marx BP, Menez U, Mackintosh MA. Using a mobile application in the management of anger problems among veterans: a pilot study. Mil Med 2016 Sep;181(9):990-995. [doi: 10.7205/MILMED-D-15-00293] [Medline: 27612342]

79. Mackintosh MA, Niehaus J, Taft CT, Marx BP, Grubbs K, Morland LA. Using a mobile application in the treatment of dysregulated anger among veterans. Mil Med 2017 Nov;182(11):e1941-e1949. [doi: 10.7205/MILMED-D-17-00063] [Medline: 29087863]

80. Ly KH, Trüschel A, Jarl L, Magnusson S, Windahl T, Johansson R, et al. Behavioural activation versus mindfulness-based guided self-help treatment administered through a smartphone application: a randomised controlled trial. BMJ Open 2014 Jan 9;4(1):e003440 [FREE Full text] [doi: 10.1136/bmjopen-2013-003440] [Medline: 24413342]

81. Kuhn E, Eftekhari A, Hoffman JE, Crowley JJ, Ramsey KM, Reger GM, et al. Clinician perceptions of using a smartphone app with prolonged exposure therapy. Adm Policy Ment Health 2014 Nov;41(6):800-807. [doi: 10.1007/s10488-013-0532-2] [Medline: 24398700]

82. Kuhn E, Crowley JJ, Hoffman JE, Eftekhari A, Ramsey KM, Owen JE, et al. Clinician characteristics and perceptions related to use of the PE (prolonged exposure) coach mobile app. Prof Psychol Res Pr 2015;46(6):437-443 [FREE Full text] [doi: 10.1037/pro0000051]

83. Reger GM, Skopp NA, Edwards-Stewart A, Lemus EL. Comparison of prolonged exposure (PE) coach to treatment as usual: a case series with two active duty soldiers. Mil Psychol 2015;27(5):287-296 [FREE Full text] [doi:

$10.1037 / \mathrm{mil} 0000083]$

84. Reger G, Browne KC, Campellone TR, Simons C, Kuhn E, Fortney JC, et al. Barriers and facilitators to mobile application use during PTSD treatment: Clinician adoption of PE coach. Prof Psychol Res Pr 2017;48(6):510-517 [FREE Full text] [doi: $10.1037 /$ pro0000153]

85. Kuhn E, Kanuri N, Hoffman JE, Garvert DW, Ruzek JI, Taylor CB. A randomized controlled trial of a smartphone app for posttraumatic stress disorder symptoms. J Consult Clin Psychol 2017 Mar;85(3):267-273. [doi: 10.1037/ccp0000163] [Medline: 28221061]

86. Possemato K, Kuhn E, Johnson EM, Hoffman JE, Brooks E. Development and refinement of a clinician intervention to facilitate primary care patient use of the PTSD Coach app. Transl Behav Med 2017 Mar;7(1):116-126 [FREE Full text] [doi: 10.1007/s13142-016-0393-9] [Medline: 27234150]

87. Miner A, Kuhn E, Hoffman JE, Owen JE, Ruzek JI, Taylor CB. Feasibility, acceptability, and potential efficacy of the PTSD Coach app: a pilot randomized controlled trial with community trauma survivors. Psychol Trauma 2016 May;8(3):384-392. [doi: 10.1037/tra0000092] [Medline: 27046668]

88. Owen JE, Jaworski BK, Kuhn E, Makin-Byrd KN, Ramsey KM, Hoffman JE. mHealth in the wild: using novel data to examine the reach, use, and impact of PTSD coach. JMIR Ment Health 2015;2(1):e7 [FREE Full text] [doi: 10.2196/mental.3935] [Medline: 26543913]

89. Possemato K, Kuhn E, Johnson E, Hoffman JE, Owen JE, Kanuri N, et al. Using PTSD Coach in primary care with and without clinician support: a pilot randomized controlled trial. Gen Hosp Psychiatry 2016;38:94-98. [doi: 10.1016/j.genhosppsych.2015.09.005] [Medline: 26589765]

90. Kuhn E, van der Meer C, Owen JE, Hoffman JE, Cash R, Carrese P, et al. PTSD Coach around the world. Mhealth 2018;4:15 [FREE Full text] [doi: 10.21037/mhealth.2018.05.01] [Medline: 29963560]

91. Cernvall M, Sveen J, Johannesson KB, Arnberg F. A pilot study of user satisfaction and perceived helpfulness of the Swedish version of the mobile app PTSD Coach. Eur J Psychotraumatol 2018;9(Suppl 1):1472990 [FREE Full text] [doi: 10.1080/20008198.2018.1472990] [Medline: 29805783]

92. de Almeida RS, Martins C, Marques A, Benevides D, Costa A, Queirós C, et al. Development of a hybrid application for psychotic disorders self-management. In: Advances in Intelligent Systems and Computing. Volume 615. Cham: Springer; 2017:229-237.

93. Terp M, Jørgensen R, Laursen BS, Mainz J, Bjørnes CD. A smartphone app to foster power in the everyday management of living with schizophrenia: qualitative analysis of young adults' perspectives. JMIR Ment Health 2018 Oct 1;5(4):e10157 [FREE Full text] [doi: 10.2196/10157] [Medline: $\underline{\text { 30274966] }}$ 
94. Bell IH, Fielding-Smith SF, Hayward M, Rossell SL, Lim MH, Farhall J, et al. Smartphone-based ecological momentary assessment and intervention in a coping-focused intervention for hearing voices (SAVVy): study protocol for a pilot randomised controlled trial. Trials 2018 May 2;19(1):262 [FREE Full text] [doi: 10.1186/s13063-018-2607-6] [Medline: 29720208]

95. Bell IH, Fielding-Smith SF, Hayward M, Rossell SL, Lim MH, Farhall J, et al. Smartphone-based ecological momentary assessment and intervention in a blended coping-focused therapy for distressing voices: Development and case illustration. Internet Interv 2018 Dec;14:18-25 [FREE Full text] [doi: 10.1016/j.invent.2018.11.001] [Medline: 30510910]

96. Garety PA, Ward T, Freeman D, Fowler D, Emsley R, Dunn G, et al. SlowMo, a digital therapy targeting reasoning in paranoia, versus treatment as usual in the treatment of people who fear harm from others: study protocol for a randomised controlled trial. Trials 2017 Nov 2;18(1):510 [FREE Full text] [doi: 10.1186/s13063-017-2242-7] [Medline: 29096681]

97. Husain N, Gire N, Kelly J, Duxbury J, McKeown M, Riley M, et al. TechCare: mobile assessment and therapy for psychosis - an intervention for clients in the Early Intervention Service: a feasibility study protocol. SAGE Open Med 2016;4:2050312116669613 [FREE Full text] [doi: 10.1177/2050312116669613] [Medline: 27790373]

98. Jongeneel A, Scheffers D, Tromp N, Nuij C, Delespaul P, Riper H, et al. Reducing distress and improving social functioning in daily life in people with auditory verbal hallucinations: study protocol for the 'Temstem' randomised controlled trial. BMJ Open 2018 Mar 6;8(3):e020537 [FREE Full text] [doi: 10.1136/bmjopen-2017-020537] [Medline: 29511020]

99. Bucci S, Barrowclough C, Ainsworth J, Morris R, Berry K, Machin M, et al. Using mobile technology to deliver a cognitive behaviour therapy-informed intervention in early psychosis (Actissist): study protocol for a randomised controlled trial. Trials 2015 Sep 10;16:404 [FREE Full text] [doi: 10.1186/s13063-015-0943-3] [Medline: 26357943]

100. Bucci S, Barrowclough C, Ainsworth J, Machin M, Morris R, Berry K, et al. Actissist: proof-of-concept trial of a theory-driven digital intervention for psychosis. Schizophr Bull 2018 Aug 20;44(5):1070-1080 [FREE Full text] [doi: 10.1093/schbul/sby032] [Medline: 29566206]

101. Ben-Zeev D, Kaiser SM, Brenner CJ, Begale M, Duffecy J, Mohr DC. Development and usability testing of FOCUS: a smartphone system for self-management of schizophrenia. Psychiatr Rehabil J 2013 Dec;36(4):289-296 [FREE Full text] [doi: 10.1037/prj0000019] [Medline: 24015913]

102. Ben-Zeev D, Brenner CJ, Begale M, Duffecy J, Mohr DC, Mueser KT. Feasibility, acceptability, and preliminary efficacy of a smartphone intervention for schizophrenia. Schizophr Bull 2014 Nov;40(6):1244-1253 [FREE Full text] [doi: 10.1093/schbul/sbu033] [Medline: 24609454]

103. Kim S, Lee GY, Yu HY, Jung EI, Lee JY, Kim SY, et al. Development and feasibility of smartphone application for cognitive-behavioural case management of individuals with early psychosis. Early Interv Psychiatry 2018 Dec;12(6):1087-1093. [doi: 10.1111/eip.12418] [Medline: 28516480]

104. Schlosser D, Campellone T, Kim D, Truong B, Vergani S, Ward C, et al. Feasibility of PRIME: a cognitive neuroscience-informed mobile app intervention to enhance motivated behavior and improve quality of life in recent onset schizophrenia. JMIR Res Protoc 2016 Apr 28;5(2):e77 [FREE Full text] [doi: 10.2196/resprot.5450] [Medline: 27125771]

105. Schlosser DA, Campellone TR, Truong B, Etter K, Vergani S, Komaiko K, et al. Efficacy of PRIME, a mobile app intervention designed to improve motivation in young people with schizophrenia. Schizophr Bull 2018 Aug 20;44(5):1010-1020 [FREE Full text] [doi: 10.1093/schbul/sby078] [Medline: 29939367]

106. Crane D, Garnett C, Michie S, West R, Brown J. A smartphone app to reduce excessive alcohol consumption: identifying the effectiveness of intervention components in a factorial randomised control trial. Sci Rep 2018 Mar 12;8(1):4384 [FREE Full text] [doi: 10.1038/s41598-018-22420-8] [Medline: 29531280]

107. Abrantes AM, Blevins C, Lindsay C, Battle CL, Buman MP, Agu E, et al. Formative work in the development of a physical activity smartphone app targeted for patients with alcohol use disorders. Psychol Sport Exerc 2019;41:162-171. [doi: 10.1016/j.psychsport.2018.02.007]

108. Leonard NR, Silverman M, Sherpa DP, Naegle MA, Kim H, Coffman DL, et al. Mobile health technology using a wearable sensorband for female college students with problem drinking: an acceptability and feasibility study. JMIR Mhealth Uhealth 2017 Jul 7;5(7):e90 [FREE Full text] [doi: 10.2196/mhealth.7399] [Medline: 28687533]

109. Liang D, Han H, Du J, Zhao M, Hser Y. A pilot study of a smartphone application supporting recovery from drug addiction. J Subst Abuse Treat 2018 May;88:51-58 [FREE Full text] [doi: 10.1016/j.jsat.2018.02.006] [Medline: 29606226]

110. Quanbeck A, Gustafson DH, Marsch LA, Chih MY, Kornfield R, McTavish F, et al. Implementing a mobile health system to integrate the treatment of addiction into primary care: a hybrid implementation-effectiveness study. J Med Internet Res 2018 Jan 30;20(1):e37 [FREE Full text] [doi: 10.2196/jmir.8928] [Medline: 29382624]

111. Zeng EY, Vilardaga R, Heffner JL, Mull KE, Bricker JB. Predictors of utilization of a novel smoking cessation smartphone app. Telemed J E Health 2015 Dec;21(12):998-1004 [FREE Full text] [doi: 10.1089/tmj.2014.0232] [Medline: 26171733]

112. Alsharif AH, Philip N. Cognitive Behavioural Therapy Embedding Smoking Cessation Program Using Smart Phone Technologies. In: Proceedings of the 2015 5th World Congress on Information and Communication Technologies. 2015 Presented at: WICT'15; December 14-16, 2015; Marrakesh, Morocco p. 134-139. [doi: 10.1109/wict.2015.7489660]

113. Jódar-Sánchez F, Hernández LC, Núñez-Benjumea FJ, González MA, Conde JM, Calderón CL, et al. Using the social-local-mobile app for smoking cessation in the SmokeFreeBrain project: protocol for a randomized controlled trial. JMIR Res Protoc 2018 Dec 6;7(12):e12464 [FREE Full text] [doi: 10.2196/12464] [Medline: 30522992] 
114. Dennis ML, Scott CK, Funk RR, Nicholson L. A pilot study to examine the feasibility and potential effectiveness of using smartphones to provide recovery support for adolescents. Subst Abus 2015;36(4):486-492 [FREE Full text] [doi: 10.1080/08897077.2014.970323] [Medline: 25310057]

115. Scott CK, Dennis ML, Gustafson DH. Using smartphones to decrease substance use via self-monitoring and recovery support: study protocol for a randomized control trial. Trials 2017 Aug 10;18(1):374 [FREE Full text] [doi: 10.1186/s13063-017-2096-z] [Medline: 28797307]

116. Mellentin AI, Nielsen B, Nielsen AS, Yu F, Stenager E. A randomized controlled study of exposure therapy as aftercare for alcohol use disorder: study protocol. BMC Psychiatry 2016 Apr 21;16:112 [FREE Full text] [doi: 10.1186/s12888-016-0795-8] [Medline: 27098817]

117. Mellentin AI, Stenager E, Nielsen B, Nielsen AS, Yu F. A smarter pathway for delivering cue exposure therapy? The design and development of a smartphone app targeting alcohol use disorder. JMIR Mhealth Uhealth 2017 Jan 30;5(1):e5 [FREE Full text] [doi: 10.2196/mhealth.6500] [Medline: 28137701]

118. Lawn S, van Agteren J, Zabeen S, Bertossa S, Barton C, Stewart J. Adapting, pilot testing and evaluating the Kick.it app to support smoking cessation for smokers with severe mental illness: a study protocol. Int J Environ Res Public Health 2018 Feb 3;15(2):pii: E254 [FREE Full text] [doi: 10.3390/ijerph15020254] [Medline: 30720772]

119. van Agteren JE, Lawn S, Bonevski B, Smith BJ. Kick.it: the development of an evidence-based smoking cessation smartphone app. Transl Behav Med 2018 Mar 1;8(2):243-267. [doi: 10.1093/tbm/ibx031] [Medline: 29447386]

120. Businelle MS, Ma P, Kendzor DE, Frank SG, Vidrine DJ, Wetter DW. An ecological momentary intervention for smoking cessation: Evaluation of feasibility and effectiveness. J Med Internet Res 2016 Dec 12;18(12):e321 [FREE Full text] [doi: 10.2196/jmir.6058] [Medline: 27956375]

121. Hébert ET, Stevens EM, Frank SG, Kendzor DE, Wetter DW, Zvolensky MJ, et al. An ecological momentary intervention for smoking cessation: the associations of just-in-time, tailored messages with lapse risk factors. Addict Behav 2018 Mar;78:30-35 [FREE Full text] [doi: 10.1016/j.addbeh.2017.10.026] [Medline: 29121530]

122. Christoforou M, Fonseca JA, Tsakanikos E. Two novel cognitive behavioral therapy-based mobile apps for agoraphobia: randomized controlled trial. J Med Internet Res 2017 Nov 24;19(11):e398 [FREE Full text] [doi: 10.2196/jmir.7747] [Medline: 29175809]

123. Ivanova E, Lindner P, Ly KH, Dahlin M, Vernmark K, Andersson G, et al. Guided and unguided Acceptance and Commitment Therapy for social anxiety disorder and/or panic disorder provided via the Internet and a smartphone application: a randomized controlled trial. J Anxiety Disord 2016 Dec;44:27-35. [doi: 10.1016/j.janxdis.2016.09.012] [Medline: 27721123]

124. Carper MM. Multimedia field test thinking about exposures? There's an app for that!. Cogn Behav Pract 2017 Feb;24(1):121-127 [FREE Full text] [doi: 10.1016/j.cbpra.2016.11.001] [Medline: 28757791]

125. Michelle TQ, Jarzabek S, Wadhwa B. CBT Assistant: mHealth App for Psychotherapy. In: Proceedings of the 2014 IEEE Global Humanitarian Technology Conference - South Asia Satellite. 2014 Presented at: GHTC-SAS'14; September 26-27, 2014; Trivandrum, India p. 135-140 URL: https://doi.org/10.1109/GHTC-SAS.2014.6967572 [doi: 10.1109/ghtc-sas.2014.6967572]

126. Boettcher J, Magnusson K, Marklund A, Berglund E, Blomdahl R, Braun U, et al. Adding a smartphone app to internet-based self-help for social anxiety: a randomized controlled trial. Comput Hum Behav 2018;87:98-108. [doi: 10.1016/j.chb.2018.04.052]

127. Szigethy E, Solano F, Wallace M, Perry DL, Morrell L, Scott K, et al. A study protocol for a non-randomised comparison trial evaluating the feasibility and effectiveness of a mobile cognitive-behavioural programme with integrated coaching for anxious adults in primary care. BMJ Open 2018 Jan 13;8(1):e019108 [FREE Full text] [doi: 10.1136/bmjopen-2017-019108] [Medline: 29331971]

128. Clough BA, Casey LM. Therapy on the move: the development of a therapeutic smartphone application. Int J Cyber Behav Psychol Learn 2015;5(1):33-41 [FREE Full text] [doi: 10.4018/ijcbpl.2015010103]

129. Stupar-Rutenfrans S, Ketelaars LE, van Gisbergen MS. Beat the fear of public speaking: mobile $360^{\circ}$ video virtual reality exposure training in home environment reduces public speaking anxiety. Cyberpsychol Behav Soc Netw 2017 Oct;20(10):624-633. [doi: 10.1089/cyber.2017.0174] [Medline: 29039704]

130. Pramana G, Parmanto B, Lomas J, Lindhiem O, Kendall PC, Silk J. Using mobile health gamification to facilitate Cognitive Behavioral Therapy skills practice in child anxiety treatment: Open clinical trial. JMIR Serious Games 2018 May 10;6(2):e9 [FREE Full text] [doi: 10.2196/games.8902] [Medline: 29748165]

131. Stegemann SK, Ebenfeld L, Lehr D, Berking M, Funk B. Development of a Mobile Application for People With Panic Disorder as Augmentation for an Internet-Based Intervention. In: Proceedings of the 2013 Federated Conference on Computer Science and Information Systems. 2013 Presented at: FedCSIS'13; September 8-11, 2013; Kraków, Poland p. 1331-1337 URL: https://www.scopus.com/inward/record.uri?eid=2-s2. 0-84892495861\&partnerID=40\&md5=538ed7c5ceab852771deb97f8eb43ce0

132. Ebenfeld L, Stegemann SK, Lehr D, Ebert DD, Jazaieri H, van Ballegooijen W, et al. Efficacy of a hybrid online training for panic symptoms and agoraphobia: study protocol for a randomized controlled trial. Trials 2014 Nov 4;15:427 [FREE Full text] [doi: 10.1186/1745-6215-15-427] [Medline: 25370504] 
133. Cruz L, Rubin J, Abreu R, Ahern S, Eldardiry H, Bobrow DG. A Wearable and Mobile Intervention Delivery System for Individuals With Panic Disorder. In: Proceedings of the 14th International Conference on Mobile and Ubiquitous Multimedia. 2015 Presented at: MUM'15; November 30 - December 2, 2015; Linz, Austria p. 175-182 URL: https://doi.org/10.1145/ 2836041.2836058 [doi: 10.1145/2836041.2836058]

134. Lindner P, Ivanova E, Ly KH, Andersson G, Carlbring P. Guided and unguided CBT for social anxiety disorder and/or panic disorder via the Internet and a smartphone application: study protocol for a randomised controlled trial. Trials 2013 Dec 18;14:437 [FREE Full text] [doi: 10.1186/1745-6215-14-437] [Medline: 24351088]

135. Kumar S, Bell MJ, Juusola JL. Mobile and traditional cognitive behavioral therapy programs for generalized anxiety disorder: a cost-effectiveness analysis. PLoS One 2018;13(1):e0190554 [FREE Full text] [doi: 10.1371/journal.pone.0190554] [Medline: 29300754]

136. Benton SA, Heesacker M, Snowden SJ, Lee G. Therapist-assisted, online (TAO) intervention for anxiety in college students: TAO outperformed treatment as usual. Prof Psychol Res Pr 2016;47(5):363-371 [FREE Full text] [doi: 10.1037/pro0000097]

137. Repetto C, Gaggioli A, Pallavicini F, Cipresso P, Raspelli S, Riva G. Virtual reality and mobile phones in the treatment of generalized anxiety disorders: a phase-2 clinical trial. Pers Ubiquit Comput 2013;17(2):253-260 [FREE Full text] [doi: 10.1007/s00779-011-0467-0]

138. Brown RK, Petty S, O'Malley S, Stojanovska J, Davenport MS, Kazerooni EA, et al. Virtual reality tool simulates MRI experience. Tomography 2018 Sep;4(3):95-98 [FREE Full text] [doi: 10.18383/j.tom.2018.00023] [Medline: 30320208 ]

139. Stolz T, Schulz A, Krieger T, Vincent A, Urech A, Moser C, et al. A mobile app for social anxiety disorder: a three-arm randomized controlled trial comparing mobile and PC-based guided self-help interventions. J Consult Clin Psychol 2018 Jun;86(6):493-504. [doi: 10.1037/ccp0000301] [Medline: 29781648]

140. Levin ME, Haeger J, Pierce B, Cruz RA. Evaluating an adjunctive mobile app to enhance psychological flexibility in acceptance and commitment therapy. Behav Modif 2017 Nov;41(6):846-867. [doi: 10.1177/0145445517719661] [Medline: $\underline{\text { 28689449] }}$

141. Ben-Zeev D, Brian RM, Jonathan G, Razzano L, Pashka N, Carpenter-Song E, et al. Mobile health (mHealth) versus clinic-based group intervention for people with serious mental illness: a randomized controlled trial. Psychiatr Serv 2018 Sep 1;69(9):978-985. [doi: 10.1176/appi.ps.201800063] [Medline: 29793397]

142. Mistler LA, Ben-Zeev D, Carpenter-Song E, Brunette MF, Friedman MJ. Mobile mindfulness intervention on an acute psychiatric unit: feasibility and acceptability study. JMIR Ment Health 2017 Aug 21;4(3):e34 [FREE Full text] [doi: 10.2196/mental.7717] [Medline: 28827214]

143. Povey J, Mills PP, Dingwall KM, Lowell A, Singer J, Rotumah D, et al. Acceptability of mental health apps for aboriginal and Torres Strait Islander Australians: a qualitative study. J Med Internet Res 2016 Mar 11;18(3):e65 [FREE Full text] [doi: 10.2196/jmir.5314] [Medline: 26969043]

144. Mitrpanont J, Phandhu-Fung J, Klubdee N, Ratanalaor S, Mitrpanont T. iCare-Stress: An Integrated Mental Health Software. In: Proceedings of the 2017 2nd International Conference on Information Technology. 2017 Presented at: INCIT'17; November 2-3, 2017; Nakhonpathom, Thailand p. 1-6. [doi: 10.1109/incit.2017.8257889]

145. Mohr DC, Tomasino KN, Lattie EG, Palac HL, Kwasny MJ, Weingardt K, et al. IntelliCare: an eclectic, skills-based app suite for the treatment of depression and anxiety. J Med Internet Res 2017 Jan 5;19(1):e10 [FREE Full text] [doi: 10.2196/jmir.6645] [Medline: 28057609]

146. Bakker D, Kazantzis N, Rickwood D, Rickard N. Development and pilot evaluation of smartphone-delivered cognitive behavior therapy strategies for mood- and anxiety-related problems: MoodMission. Cogn Behav Pract 2018 Nov;25(4):496-514. [doi: 10.1016/j.cbpra.2018.07.002]

147. Addepally SA, Purkayastha S. Mobile-Application Based Cognitive Behavior Therapy (CBT) for Identifying and Managing Depression and Anxiety. In: Proceedings of the International Conference on Digital Human Modeling and Applications in Health, Safety, Ergonomics and Risk Management. 2017 Presented at: DHM'17; July 9-14, 2017; Vancouver, Canada p. 3-12 URL: https://doi.org/10.1007/978-3-319-58466-9 1 [doi: 10.1007/978-3-319-58466-9 1]

148. Proudfoot J, Clarke J, Birch MR, Whitton AE, Parker G, Manicavasagar V, et al. Impact of a mobile phone and web program on symptom and functional outcomes for people with mild-to-moderate depression, anxiety and stress: a randomised controlled trial. BMC Psychiatry 2013 Nov 18;13:312 [FREE Full text] [doi: 10.1186/1471-244X-13-312] [Medline: 24237617]

149. Fortuna KL, DiMilia PR, Lohman MC, Bruce ML, Zubritsky CD, Halaby MR, et al. Feasibility, acceptability, and preliminary effectiveness of a peer-delivered and technology supported self-management intervention for older adults with serious mental illness. Psychiatr Q 2018 Jun;89(2):293-305 [FREE Full text] [doi: 10.1007/s11126-017-9534-7] [Medline: 28948424]

150. Schroeder J, Wilkes C, Rowan K, Toledo A, Paradiso A, Czerwinski M, et al. Pocket Skills: A Conversational Mobile Web App To Support Dialectical Behavioral Therapy. In: Proceedings of the 2018 CHI Conference on Human Factors in Computing Systems. 2018 Presented at: CHI'18; April 21 - 26, 2018; Montreal, Canada p. 1-15. [doi: $10.1145 / 3173574.3173972]$

151. Almodovar AS, Surve S, Axon DR, Cooper D, Nahata MC. Self-directed engagement with a mobile app (Sinasprite) and its effects on confidence in coping skills, depression, and anxiety: retrospective longitudinal study. JMIR Mhealth Uhealth 2018 Mar 16;6(3):e64 [FREE Full text] [doi: 10.2196/mhealth.9612] [Medline: 29549066] 
152. Pramana G, Parmanto B, Kendall PC, Silk JS. The SmartCAT: an m-health platform for ecological momentary intervention in child anxiety treatment. Telemed J E Health 2014 May;20(5):419-427 [FREE Full text] [doi: 10.1089/tmj.2013.0214] [Medline: 24579913]

153. Bauer AM, Hodsdon S, Hunter S, Choi Y, Bechtel J, Fortney JC. Lessons from the deployment of the SPIRIT app to support Collaborative care for rural patients with complex psychiatric conditions. Proc ACM Int Conf Ubiquitous Comput 2017 Sep;2017:772-780 [FREE Full text] [doi: 10.1145/3123024.3125610] [Medline: 29075683]

154. Huang ST, Sano A, Kwan CM. The Moment: A Mobile Tool for People With Depression or Bipolar Disorder. In: Proceedings of the 2014 ACM International Joint Conference on Pervasive and Ubiquitous Computing: Adjunct Publication. 2014 Presented at: UbiComp'14 Adjunct; September 13-17, 2014; Seattle, USA p. 235-238 URL: https://doi.org/10.1145/2638728. 2638784 [doi: $10.1145 / 2638728.2638784]$

155. Fleming JB, Hill YN, Burns MN. Usability of a culturally informed mHealth intervention for symptoms of anxiety and depression: feedback from young sexual minority men. JMIR Hum Factors 2017 Aug 25;4(3):e22 [FREE Full text] [doi: 10.2196/humanfactors.7392] [Medline: 28842389]

156. Fortuna KL, Lohman MC, Gill LE, Bruce ML, Bartels SJ. Adapting a psychosocial intervention for smartphone delivery to middle-aged and older adults with serious mental illness. Am J Geriatr Psychiatry 2017 Aug;25(8):819-828 [FREE Full text] [doi: 10.1016/j.jagp.2016.12.007] [Medline: 28169129]

157. Mueller NE, Panch T, Macias C, Cohen BM, Ongur D, Baker JT. Using smartphone apps to promote psychiatric rehabilitation in a peer-led community support program: pilot study. JMIR Ment Health 2018 Aug 15;5(3):e10092 [FREE Full text] [doi: 10.2196/10092] [Medline: 30111526]

158. Nicholson J, Wright SM, Carlisle AM. Pre-post, mixed-methods feasibility study of the WorkingWell mobile support tool for individuals with serious mental illness in the USA: a pilot study protocol. BMJ Open 2018 Feb 6;8(2):e019936 [FREE Full text] [doi: 10.1136/bmjopen-2017-019936] [Medline: 29437756]

159. Nicholson J, Wright SM, Carlisle AM, Sweeney MA, McHugo GJ. The WorkingWell mobile phone app for individuals with serious mental illnesses: proof-of-concept, mixed-methods feasibility study. JMIR Ment Health 2018 Oct 25;5(4):e11383 [FREE Full text] [doi: 10.2196/11383] [Medline: 30361199]

160. Baumel A, Tinkelman A, Mathur N, Kane JM. Digital peer-support platform (7Cups) as an adjunct treatment for women with postpartum depression: Feasibility, acceptability, and preliminary efficacy study. JMIR Mhealth Uhealth 2018 Feb 13;6(2):e38 [FREE Full text] [doi: 10.2196/mhealth.9482] [Medline: 29439944]

161. Fuller-Tyszkiewicz M, Richardson B, Klein B, Skouteris H, Christensen H, Austin D, et al. A mobile app-based intervention for depression: end-user and expert usability testing study. JMIR Ment Health 2018 Aug 23;5(3):e54 [FREE Full text] [doi: 10.2196/mental.9445] [Medline: 30139722]

162. Giosan C, Cobeanu O, Mogoaşe C, Szentagotai A, Mureşan V, Boian R. Reducing depressive symptomatology with a smartphone app: study protocol for a randomized, placebo-controlled trial. Trials 2017 May 12;18(1):215 [FREE Full text] [doi: 10.1186/s13063-017-1960-1] [Medline: 28494802]

163. Watts S, Mackenzie A, Thomas C, Griskaitis A, Mewton L, Williams A, et al. CBT for depression: a pilot RCT comparing mobile phone vs computer. BMC Psychiatry 2013;13(1):49 [FREE Full text] [doi: 10.1186/1471-244x-13-49]

164. Deady M, Johnston DA, Glozier N, Milne D, Choi I, Mackinnon A, et al. A smartphone application for treating depressive symptoms: study protocol for a randomised controlled trial. BMC Psychiatry 2018 Jun 1;18(1):166 [FREE Full text] [doi: 10.1186/s12888-018-1752-5] [Medline: 29859060]

165. Weisel KK, Zarski A, Berger T, Schaub MP, Krieger T, Moser CT, et al. Transdiagnostic tailored internet- and mobile-based guided treatment for major depressive disorder and comorbid anxiety: study protocol of a randomized controlled trial. Front Psychiatry 2018;9:274 [FREE Full text] [doi: 10.3389/fpsyt.2018.00274] [Medline: 30022954]

166. Mohr DC, Stiles-Shields C, Brenner C, Palac H, Montague E, Kaiser SM, et al. MedLink: a mobile intervention to address failure points in the treatment of depression in general medicine. Int Conf Pervasive Comput Technol Healthc 2015 May;2015:100-107 [FREE Full text] [doi: 10.4108/icst.pervasivehealth.2015.259042] [Medline: 26640740]

167. Wahle F, Kowatsch T, Fleisch E, Rufer M, Weidt S. Mobile sensing and support for people with depression: a pilot trial in the wild. JMIR Mhealth Uhealth 2016 Sep 21;4(3):e111 [FREE Full text] [doi: 10.2196/mhealth.5960] [Medline: 27655245]

168. Birney AJ, Gunn R, Russell JK, Ary DV. MoodHacker mobile web app with email for adults to self-manage mild-to-moderate depression: randomized controlled trial. JMIR Mhealth Uhealth 2016 Jan 26;4(1):e8 [FREE Full text] [doi: 10.2196/mhealth.4231] [Medline: 26813737]

169. Dahne J, Lejuez CW, Kustanowitz J, Felton JW, Diaz VA, Player MS, et al. Moodivate: a self-help behavioral activation mobile app for utilization in primary care-Development and clinical considerations. Int J Psychiatry Med 2017 Mar;52(2):160-175 [FREE Full text] [doi: 10.1177/0091217417720899] [Medline: 28792292]

170. Gordon M, Henderson R, Holmes JH, Wolters MK, Bennett IM, SPIRIT (Stress in Pregnancy: Improving Results with Interactive Technology) Group. Participatory design of ehealth solutions for women from vulnerable populations with perinatal depression. J Am Med Inform Assoc 2016 Jan;23(1):105-109. [doi: 10.1093/jamia/ocv109] [Medline: 26342219] 
171. Schlosser DA, Campellone TR, Truong B, Anguera JA, Vergani S, Vinogradov S, et al. The feasibility, acceptability, and outcomes of PRIME-D: A novel mobile intervention treatment for depression. Depress Anxiety 2017 Jun;34(6):546-554 [FREE Full text] [doi: 10.1002/da.22624] [Medline: 28419621]

172. Mehrotra S, Sudhir P, Rao G, Thirthalli J, Srikanth T. Development and pilot testing of an internet-based self-help intervention for depression for Indian users. Behav Sci (Basel) 2018 Mar 22;8(4):pii: E36 [FREE Full text] [doi: 10.3390/bs8040036] [Medline: 29565278]

173. Panatagama AP, Pratama GP, Wibawa DY. SocioEmpathy: A Social-Sensitivity Application to Reduce Stress and Depression of Divorce or Domestic Violence Victims. In: Proceedings of the 2018 6th International Conference on Information and Communication Technology. 2018 Presented at: ICoICT'18; May 3-5, 2018; Bandung, Indonesia p. 92-97. [doi: 10.1109/icoict.2018.8528755]

174. Takahashi K, Takada K, Hirao K. Feasibility and preliminary efficacy of a smartphone application intervention for subthreshold depression. Early Interv Psychiatry 2019 Feb;13(1):133-136. [doi: 10.1111/eip.12540] [Medline: 29356332]

175. Roepke AM, Jaffee SR, Riffle OM, McGonigal J, Broome R, Maxwell B. Randomized controlled trial of SuperBetter, a smartphone-based/internet-based self-help tool to reduce depressive symptoms. Games Health J 2015 Jun;4(3):235-246. [doi: 10.1089/g4h.2014.0046] [Medline: 26182069]

176. Caplan S, Lovera AS, Liberato PR. A feasibility study of a mental health mobile app in the Dominican Republic: the untold story. Int J Ment Health 2018;47(4):311-345. [doi: 10.1080/00207411.2018.1553486]

177. Stiles-Shields C, Montague E, Lattie EG, Schueller SM, Kwasny MJ, Mohr DC. Exploring user learnability and learning performance in an app for depression: usability study. JMIR Hum Factors 2017 Aug 11;4(3):e18 [FREE Full text] [doi: 10.2196/humanfactors.7951] [Medline: 28801301]

178. Hur JW, Kim B, Park D, Choi SW. A scenario-based cognitive behavioral therapy mobile app to reduce dysfunctional beliefs in individuals with depression: a randomized controlled trial. Telemed J E Health 2018 Sep;24(9):710-716. [doi: 10.1089/tmj.2017.0214] [Medline: 29323626]

179. Watanabe N, Horikoshi M, Yamada M, Shimodera S, Akechi T, Miki K, Steering Committee of the Fun to Learn to Act and Think through Technology Project. Adding smartphone-based cognitive-behavior therapy to pharmacotherapy for major depression (FLATT project): study protocol for a randomized controlled trial. Trials 2015 Jul 7;16:293 [FREE Full text] [doi: 10.1186/s13063-015-0805-z] [Medline: 26149441]

180. Mantani A, Kato T, Furukawa TA, Horikoshi M, Imai H, Hiroe T, et al. Smartphone cognitive behavioral therapy as an adjunct to pharmacotherapy for refractory depression: Randomized controlled trial. J Med Internet Res 2017 Nov 3;19(11):e373 [FREE Full text] [doi: 10.2196/jmir.8602] [Medline: 29101095]

181. Furukawa TA, Horikoshi M, Fujita H, Tsujino N, Jinnin R, Kako Y, et al. Cognitive and behavioral skills exercises completed by patients with major depression during smartphone cognitive behavioral therapy: Secondary analysis of a randomized controlled trial. JMIR Ment Health 2018 Jan 11;5(1):e4 [FREE Full text] [doi: 10.2196/mental.9092] [Medline: 29326098]

182. Hung GL, Yang PC, Wang CY, Chiang JH. A Smartphone-Based Personalized Activity Recommender System for Patients with Depression. In: Proceedings of the 5th EAI International Conference on Wireless Mobile Communication and Healthcare. 2015 Presented at: MOBIHEALTH'15; October 14-16, 2015; London p. 253-257 URL: https://doi.org/10.4108/eai.14-10-2015. 2261655 [doi: 10.4108/eai.14-10-2015.2261655]

183. Anguera JA, Jordan JT, Castaneda D, Gazzaley A, Areán PA. Conducting a fully mobile and randomised clinical trial for depression: access, engagement and expense. BMJ Innov 2016 Jan;2(1):14-21 [FREE Full text] [doi: 10.1136/bmjinnov-2015-000098] [Medline: 27019745]

184. Giosan C, Mogoaşe C, Cobeanu O, Tătar AS, Mureşan V, Boian R. Using a smartphone app to reduce cognitive vulnerability and mild depressive symptoms: Study protocol of an exploratory randomized controlled trial. Trials 2016 Dec 28;17(1):609 [FREE Full text] [doi: 10.1186/s13063-016-1740-3] [Medline: 28031038]

185. Yoo JS, Kim IS, Gwon JA. Design and implementation of smartphone application for measurement and management of depressive emotions in adolescents using cognitive behavioral therapy. In: HCI International 2017 - Posters' Extended Abstracts. Cham: Springer; 2017:317-323.

186. Lüdtke T, Westermann S, Pult LK, Schneider BC, Pfuhl G, Moritz S. Evaluation of a brief unguided psychological online intervention for depression: a controlled trial including exploratory moderator analyses. Internet Interv 2018 Sep;13:73-81 [FREE Full text] [doi: 10.1016/j.invent.2018.06.004] [Medline: 30206522]

187. Vázquez FL, Torres A, Díaz O, Páramo M, Otero P, Blanco V, et al. Cognitive behavioral intervention via a smartphone app for non-professional caregivers with depressive symptoms: study protocol for a randomized controlled trial. Trials 2018 Jul 31;19(1):414 [FREE Full text] [doi: 10.1186/s13063-018-2793-2] [Medline: 30064466]

188. World Health Organization. Mental Health Atlas 2017. Geneva: World Health Organization; 2018.

189. González-González S, González M, García MC, Ruiz M, Rojo MV, Sandoya M, et al. Psychological treatments features and outcomes in Spanish public mental health centres. Int J Psychol Psychol Ther 2014;14(1):17-32 [FREE Full text]

190. Griffiths KM, Christensen H. Internet-based mental health programs: a powerful tool in the rural medical kit. Aust J Rural Health 2007 Apr;15(2):81-87. [doi: 10.1111/j.1440-1584.2007.00859.x] [Medline: 17441815]

191. Kazdin AE. Technology-based interventions and reducing the burdens of mental illness: perspectives and comments on the special series. Cogn Behav Pract 2015;22(3):359-366 [FREE Full text] [doi: 10.1016/j.cbpra.2015.04.004] 
192. Kazdin AE, Blase SL. Rebooting psychotherapy research and practice to reduce the burden of mental illness. Perspect Psychol Sci 2011 Jan;6(1):21-37. [doi: 10.1177/1745691610393527] [Medline: 26162113]

193. Venkatesh V, Davis FD. A theoretical extension of the Technology Acceptance Model: four longitudinal field studies. Manag Sci 2000 Feb;46(2):186-204. [doi: 10.1287/mnsc.46.2.186.11926]

194. Huang TL, Liao S. A model of acceptance of augmented-reality interactive technology: the moderating role of cognitive innovativeness. Electron Commer Res 2015;15(2):269-295 [FREE Full text] [doi: 10.1007/s10660-014-9163-2]

195. Bullis JR, Boettcher H, Sauer - Zavala S, Farchione TJ, Barlow DH. What is an emotional disorder? A transdiagnostic mechanistic definition with implications for assessment, treatment, and prevention. Clin Psychol Sci Pract 2019 Mar 14;26(2):e12278. [doi: 10.1111/cpsp.12278]

196. Kessler RC, Berglund P, Demler O, Jin R, Merikangas KR, Walters EE. Lifetime prevalence and age-of-onset distributions of DSM-IV disorders in the National Comorbidity Survey Replication. Arch Gen Psychiatry 2005 Jun;62(6):593-602. [doi: 10.1001/archpsyc.62.6.593] [Medline: 15939837]

197. Kessler RC, Chiu WT, Demler O, Merikangas KR, Walters EE. Prevalence, severity, and comorbidity of 12-month DSM-IV disorders in the National Comorbidity Survey Replication. Arch Gen Psychiatry 2005 Jun;62(6):617-627 [FREE Full text] [doi: 10.1001/archpsyc.62.6.617] [Medline: 15939839]

198. Rapaport MH, Clary C, Fayyad R, Endicott J. Quality-of-life impairment in depressive and anxiety disorders. Am J Psychiatry 2005 Jun;162(6):1171-1178. [doi: 10.1176/appi.ajp.162.6.1171] [Medline: 15930066]

199. Andlin-Sobocki P, Wittchen HU. Cost of anxiety disorders in Europe. Eur J Neurol 2005 Jun;12(Suppl 1):39-44. [doi: 10.1111/j.1468-1331.2005.01196.x] [Medline: 15877777 ]

200. Mendlowicz MV, Stein MB. Quality of life in individuals with anxiety disorders. Am J Psychiatry 2000 May;157(5):669-682. [doi: 10.1176/appi.ajp.157.5.669] [Medline: 10784456]

201. Cuijpers P, Beekman AT, Reynolds CF. Preventing depression: a global priority. J Am Med Assoc 2012 Mar 14;307(10):1033-1034 [FREE Full text] [doi: 10.1001/jama.2012.271] [Medline: 22416097]

202. Andrews G, Basu A, Cuijpers P, Craske MG, McEvoy P, English CL, et al. Computer therapy for the anxiety and depression disorders is effective, acceptable and practical health care: An updated meta-analysis. J Anxiety Disord 2018 Apr;55:70-78 [FREE Full text] [doi: 10.1016/j.janxdis.2018.01.001] [Medline: 29422409]

203. Richards D, Richardson T. Computer-based psychological treatments for depression: a systematic review and meta-analysis. Clin Psychol Rev 2012 Jun;32(4):329-342. [doi: 10.1016/j.cpr.2012.02.004] [Medline: 22466510]

204. Gunderson JG. Borderline personality disorder: ontogeny of a diagnosis. Am J Psychiatry 2009 May;166(5):530-539 [FREE Full text] [doi: 10.1176/appi.ajp.2009.08121825] [Medline: 19411380]

205. Lenzenweger MF, Lane MC, Loranger AW, Kessler RC. DSM-IV personality disorders in the National Comorbidity Survey Replication. Biol Psychiatry 2007 Sep 15;62(6):553-564 [FREE Full text] [doi: 10.1016/j.biopsych.2006.09.019] [Medline: $\underline{17217923]}$

206. Lieb K, Zanarini MC, Schmahl C, Linehan MM, Bohus M. Borderline personality disorder. Lancet 2004;364(9432):453-461. [doi: 10.1016/S0140-6736(04)16770-6] [Medline: 15288745]

207. Giota KG, Kleftaras G. Mental health apps: innovations, risks and ethical considerations. Ehealth Telecommun Syst Netw 2014;3(3):19-23. [doi: 10.4236/etsn.2014.33003]

208. Boulos MN, Brewer AC, Karimkhani C, Buller DB, Dellavalle RP. Mobile medical and health apps: state of the art, concerns, regulatory control and certification. Online J Public Health Inform 2014;5(3):229 [FREE Full text] [doi: 10.5210/ojphi.v5i3.4814] [Medline: 24683442]

209. Baron KG, Abbott S, Jao N, Manalo N, Mullen R. Orthosomnia: are some patients taking the quantified self too far? J Clin Sleep Med 2017 Feb 15;13(2):351-354 [FREE Full text] [doi: 10.5664/jcsm.6472] [Medline: 27855740]

210. Huckvale K, Torous J, Larsen ME. Assessment of the data sharing and privacy practices of smartphone apps for depression and smoking cessation. JAMA Netw Open 2019 Apr 5;2(4):e192542 [FREE Full text] [doi:

10.1001/jamanetworkopen.2019.2542] [Medline: $\underline{31002321]}$

211. Parker L, Halter V, Karliychuk T, Grundy Q. How private is your mental health app data? An empirical study of mental health app privacy policies and practices. Int J Law Psychiatry 2019;64:198-204. [doi: 10.1016/j.ijlp.2019.04.002] [Medline: $\underline{31122630]}$

212. Berry N, Lobban F, Emsley R, Bucci S. Acceptability of interventions delivered online and through mobile phones for people who experience severe mental health problems: a systematic review. J Med Internet Res 2016 May 31;18(5):e121 [FREE Full text] [doi: 10.2196/jmir.5250] [Medline: 27245693]

213. Ackerman L. Privacy Rights Clearinghouse. 2013. Mobile Health and Fitness Applications and Information Privacy: Report to California Consumer URL: https://privacyrights.org/sites/default/files/pdfs/mobile-medical-apps-privacy-consumer-report. pdf [accessed 2020-02-07]

214. O'Loughlin K, Neary M, Adkins EC, Schueller SM. Reviewing the data security and privacy policies of mobile apps for depression. Internet Interv 2019 Mar;15:110-115 [FREE Full text] [doi: 10.1016/j.invent.2018.12.001] [Medline: 30792962]

215. Harris KD. State of California - Office of the Attorney General. 2013 Jan. Privacy on the Go: Recommendations for the Mobile Ecosystem URL: http://oag.ca.gov/sites/all/files/agweb/pdfs/privacy/privacy_on_the_go.pdf [accessed 2018-03-09] 
216. Mense A, Steger S, Sulek M, Jukic-Sunaric D, Mészáros A. Analyzing privacy risks of mHealth applications. Stud Health Technol Inform 2016;221:41-45 [FREE Full text] [Medline: 27071873]

217. Kazdin AE, Rabbitt SM. Novel models for delivering mental health services and reducing the burdens of mental illness. Clin Psychol Sci 2013;1(2):170-191. [doi: 10.1177/2167702612463566]

218. Olff M. Mobile mental health: a challenging research agenda. Eur J Psychotraumatol 2015;6:27882 [FREE Full text] [doi: 10.3402/ejpt.v6.27882] [Medline: 25994025]

219. EUR-Lex. Regulation (EU). (2017). 2017/745 of the European parliament and of the council of 5 April 2017 on medical devices, amending Directive 2001/83/EC, Regulation (EC) No 178/2002 and Regulation (EC) No 1223/2009 and repealing Council Directives 90/385/EEC and 93/42/EEC URL: https://eur-lex.europa.eu/legal-content/EN/TXT/ ?uri=CELEX\%3A32017R0745 [accessed 2018-03-09]

220. EUR-Lex. 2016. Regulation (EU) 2016/679 of the European Parliament and of the Council of 27 April 2016 on the protection of natural persons with regard to the processing of personal data and on the free movement of such data, and repealing Directive 95/46 URL: https://eur-lex.europa.eu/legal-content/EN/TXT/PDF/?uri=CELEX:32016R0679 [accessed 2020-02-05]

221. US Food and Drug Administration, US Department of Health and Human Services, Center for Devices and Radiological Health, Center for Biologics Evaluation and Research. Food and Drug Administration. Policy for Device Software Functions and Mobile Medical Applications. Guidance for Industry and Food and Drug Administration Staff URL: https://www. fda.gov/media/80958/download [accessed 2019-10-01]

222. Fox G, Connolly R. Mobile health technology adoption across generations: narrowing the digital divide. Info Syst $\mathbf{J}$ 2018;28(6):995-1019 [FREE Full text] [doi: 10.1111/isj.12179]

223. Chiauzzi E, Newell A. Mental health apps in psychiatric treatment: a patient perspective on real world technology usage. JMIR Ment Health 2019 Apr 22;6(4):e12292 [FREE Full text] [doi: 10.2196/12292] [Medline: $\underline{31008711]}$

224. Osma J, Sprenger M, Mettler T. Introduction of e-mental health in national health systems - a health professionals' perspective. Health Policy Technol 2017;6(4):436-445. [doi: 10.1016/j.hlpt.2017.07.001]

225. Lipschitz J, Miller CJ, Hogan TP, Burdick KE, Lippin-Foster R, Simon SR, et al. Adoption of mobile apps for depression and anxiety: cross-sectional survey study on patient interest and barriers to engagement. JMIR Ment Health 2019 Jan 25;6(1):e11334 [FREE Full text] [doi: 10.2196/11334] [Medline: 30681968]

226. Simblett S, Matcham F, Siddi S, Bulgari V, di San Pietro CB, López JH, RADAR-CNS Consortium. Barriers to and facilitators of engagement With mHealth technology for remote measurement and management of depression: Qualitative analysis. JMIR Mhealth Uhealth 2019 Jan 30;7(1):e11325 [FREE Full text] [doi: 10.2196/11325] [Medline: 30698535]

\author{
Abbreviations \\ APA: American Psychological Association \\ CBT: cognitive behavioral therapy \\ DSM: Diagnostic and Statistical Manual of Mental Disorders \\ EC: exclusion criteria \\ eHealth: electronic health \\ EMI: ecological momentary intervention \\ EU: European Union \\ IC: inclusion criteria \\ ICT: information and communication technologies \\ MEDLINE: Medical Literature Analysis and Retrieval System Online \\ mHealth: mobile health \\ PRISMA: Preferred Reporting Items for Systematic Reviews and Meta-Analyses \\ RCT: randomized controlled trial \\ UX: user experience \\ VR: virtual reality \\ WoS: Web of Science
}

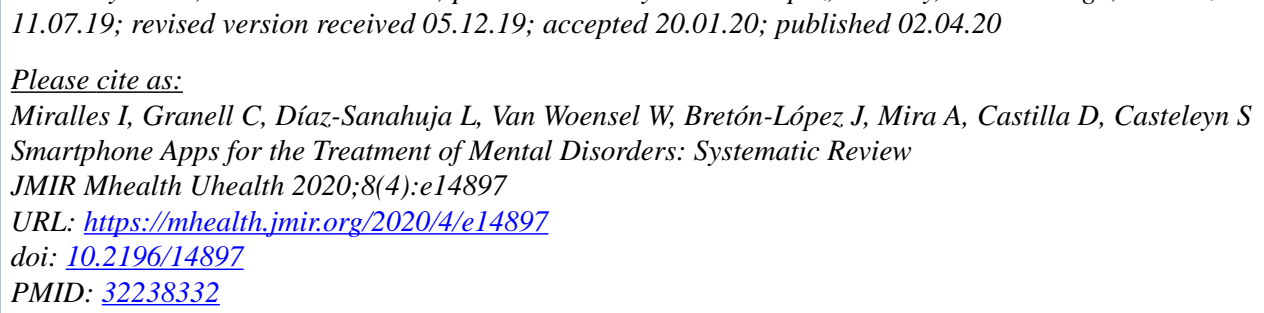


CIgnacio Miralles, Carlos Granell, Laura Díaz-Sanahuja, William Van Woensel, Juana Bretón-López, Adriana Mira, Diana Castilla, Sven Casteleyn. Originally published in JMIR mHealth and uHealth (http://mhealth.jmir.org), 02.04.2020. This is an open-access article distributed under the terms of the Creative Commons Attribution License (https://creativecommons.org/licenses/by/4.0/), which permits unrestricted use, distribution, and reproduction in any medium, provided the original work, first published in JMIR mHealth and uHealth, is properly cited. The complete bibliographic information, a link to the original publication on http://mhealth.jmir.org/, as well as this copyright and license information must be included. 